
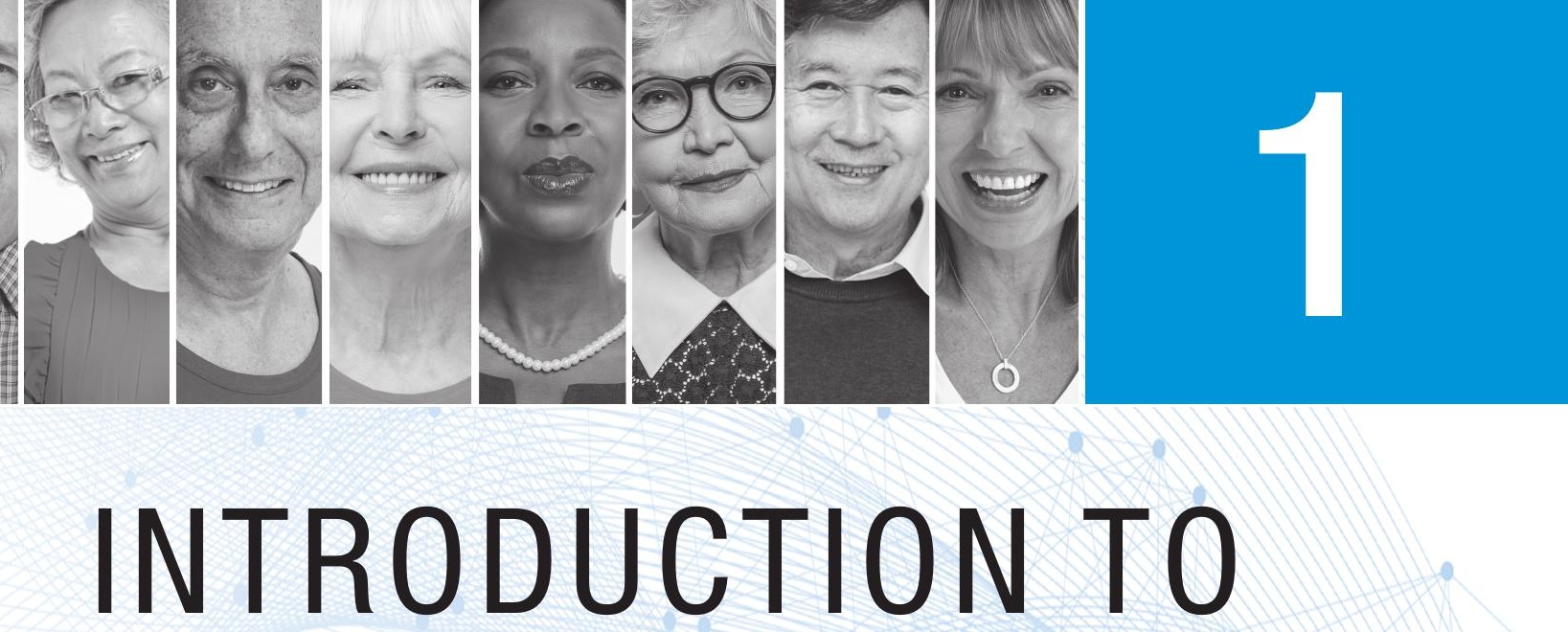

HEALTH PROMOTION

\title{
AND AGING
}

\section{KEY TERMS}

Healthy People initiatives

libertarian paternalism

baby boomers versus the older old

health promotion and disease

prevention

age rectangle

activities of daily living and instrumental activities of daily living

chronic conditions and disability

centenarians and supercentenarians

causes of death

sociodemographic trends: marital status, educational status, poverty, Internet access, political power labor force participation rate racial and ethnic composition acculturation

extraordinary accomplishment primary, secondary, and tertiary prevention seven dimensions of wellness antiaging versus proaging compression of morbidity health expectancy versus life expectancy

intergenerational conflict Medicare, Medicaid, and Social Security medical care, healthcare, and quality care 


\section{LEARNING OBJECTIVES}

- Critically evaluate the role of the federal government in promoting health.

- Create your own hypothetical example of libertarian paternalism.

- Explain your opinion on whether health promotion, disease prevention, and chronic disease management save money.

- Describe the impact of sociodemographic trends on healthy aging.

- Contrast the baby boomers and the older old.

- Differentiate chronic disease and disability.

- Examine the pros and cons of becoming a centenarian.

- Review trends in life expectancy.

- Identify leading causes of death.

- Examine hospital, physician, and medication trends.

- Identify labor force participation rates among older adults.

- Contrast Internet use of boomers versus that of older adults.

- Examine the consequences of rising educational levels on older adults.

- Describe older adult poverty.

- Identify trends in older adult racial/ethnic composition.

- Contrast definitions of healthy aging, and construct your own definition.

- Identify an extraordinary accomplishment of an older adult that appeals to you.

- Distinguish among primary, secondary, and tertiary prevention.

- Evaluate the antiaging movement.

- Define compression of morbidity and analyze its likely future course.

- Contrast health expectancy with life expectancy.

- Contrast physical versus emotional aspects of aging.

- Explore the potential for intergenerational conflict over healthcare.

- Describe the Medicare, Medicaid, and Social Security programs.

- Explain why medical care and healthcare are not synonymous.

Youth, large, lusty, loving-youth full of grace, force, fascination. Do you know that Old Age may come after you with equal grace, force, fascination?

Did you know that the federal government establishes goals for healthy aging? As far back as 1990, the U.S. Public Health Service established the goal of increasing the number of years of healthy life remaining at age 65 from 11.8 years, as it was in 1990, to 14 years by 2000. It turned out, however, that this goal for the decade was not close to being met-it was extended by only 4 months. Undeterred, many more goals were set during this and subsequent decades. This raises some interesting questions: Why is the federal government doing this? Should it be doing this? Is it helping to promote healthy aging? 


\section{HEALTHY PEOPLE INITIATIVES}

In 1979, one of the most influential documents in the field of health promotion, Healthy People: The Surgeon General's Report on Health Promotion and Disease Prevention, was published (U.S. Department of Health and Human Services [USDHHS], 1979). Over the years this report was widely cited by the popular media as well as in professional journals and at health conferences. Many attribute to it a seminal role in fostering health-promoting initiatives throughout the nation.

It was closely followed by another report, and a call to action, by the U.S. Public Health Service in 1980, Promoting Health/Preventing Disease: Objectives for the Nation, which outlined health objectives for this country to achieve over the following 10 years. A decade later, in 1990, another national effort, Healthy People 2000, was initiated by the U.S. Public Health Service in an effort to reduce preventable death and disability for Americans by the year 2000. This was followed by Healthy People 2010, 2020, and, currently in the planning stage, 2030.

As can be seen in Table 1.1, I selected three of the objectives that were set for this decade that address the health of older adults and that received minimal to no support. I call these objectives "wishful thinking," as evidenced by the lack of "Mid-Course Progress."

\section{TABLE 1.1 HEALTHY PEOPLE 2020-MID-COURSE PROGRESS}

1. Objective: Reduce the proportion of older adults who have moderate to severe functional limitations

Baseline: $29.3 \%$ of older adults had moderate to severe functional limitations in 2007

Target: $26.4 \%$ in 2020

Mid-Course Progress: $32.2 \%$

2. Objective: Increase the proportion of the healthcare workforce with geriatric certification

a. Physicians

Baseline: $2.7 \%$ of physicians had geriatric certification in 2009

Target: $3 \%$ in 2020

Mid-Course Progress: $2.5 \%$

b. Geriatric Psychiatrists

Baseline: $4.3 \%$ of geriatric psychiatrists had geriatric certification in 2009

Target: $4.7 \%$ in 2020

Mid-Course Progress: $4.2 \%$

c. Registered Nurses

Baseline: $1.4 \%$ of registered nurses had geriatric certification in 2004

Target: $1.5 \%$ in 2020

Mid-Course Progress: 0.5\%

3. Objective: Reduce the rate of emergency department visits due to falls among older adults

Baseline: 5,235 emergency department visits per 100,000 older adults in 2007

Target: 4,711 in 2020

Mid-Course Progress: 6,893

Source: National Center for Health Statistics. (2016). Healthy People 2020: Midcourse review (pp. 31-7-31-8).

Washington, DC: U.S. Department of Health and Human Services. Retrieved from https://www.cdc.gov/nchs/data/ hpdata2020/HP2020MCR-C31-OA.pdf 
The majority of Healthy People initiatives affecting older adults did not receive adequate, or any, support to achieve their objectives. Of the 12 measurable Healthy People 2020 objectives for which mid-course data were available in the "Older Adults Topic Area," three objectives met or exceeded their 2020 targets, one improved, three had little or no change, and five got worse-including the three in Table 1.1.

In one area in which there had been no financial support for encouraging changebeing overweight or obese-the trend in the United States for adults up to age 74 moved in the opposite direction. There has been a steady increase in weight gain for Americans of all ages, decade after decade.

There has been a similar negative outcome with respect to sedentary behavior among Americans. In the absence of financial support for encouraging behavior change, the average amount of light-to-moderate physical activity performed on a near-daily basis by those between the ages of 18 and 74 has not improved over the decades.

Focusing on those age 65 and over, the Merck Institute on Aging and Health cited results from the Healthy People 2010 initiative and reported many failing grades. Older Americans fell short of the 2010 target goals for not only physical activity and obesity, but also eating fruits and vegetables, edentulism (loss of teeth), and reducing hip fractures and fall-related deaths. Again, financial support for achieving target goals was largely or completely absent.

In contrast to the mere monitoring of most Healthy People 2010 target goals, financial assistance was provided to older adults through Medicare for medical screenings and immunizations. Thus, cholesterol, colorectal, and mammogram screening goals were met; pneumococcal and influenza vaccination goals were financially supported and could have been met-after all, the percentage of compliance in these two areas doubled during the decade- but the target goals were unrealistically set at $90 \%$ of the older population.

Another goal — to achieve less than $12 \%$ of the older adult population smoking-also received financial support and was met. The support came mostly from states through the tobacco industry settlement to cover Medicaid expenses caused by smoking-related illnesses (though some states wound up diverting resources to nonhealth purposes) and, to a much lesser extent, through smoking cessation coverage by Medicare.

On the positive side, the Healthy People initiatives are focused on documenting baselines, setting objectives, and monitoring progress. This at least informs us on what the health problems are and whether they are getting better or worse.

Setting healthcare priorities is no longer a matter of tabulating the number of deaths from a few diseases and then organizing a campaign against the most prevalent ones, like a "war on heart disease" or a "war on cancer." The Healthy People initiatives are health oriented, not disease oriented, and are not as simple as lobbying for more research money to cure a disease. Instead, health-promoting initiatives involve the complexity of the socioeconomic, lifestyle, and other nonmedical influences that impact our ability to attain and maintain health.

Many Americans feel: "Mind your own business, government. I am responsible for my lifestyle and whether I want to improve my health." This raises questions in the minds of those on the right of the political spectrum: conservatives and lib-

QUESTION: What do you think is the most

important health objective to set for older adults

for the Healthy People 2030 initiative? Why?

What should the federal and state governments,

health professionals, and laypersons do, if

anything, to help achieve this objective? ertarians (see Box 1.1). Why should the federal government be involved at all? Isn't health promotion an individual's responsibility?

The basic premise of libertarian paternalism is that people are busy, lives are complicated, and even intelligent people can make foolish health or 


\section{BOX 1.1 Libertarian Paternalism}

The author is not thrilled with the effectiveness of Healthy People initiatives, but libertarian paternalists may be more sympathetic toward a government intervention if a compromise method for achieving specific health goals is used. What is a libertarian paternalist, you ask?

A libertarian paternalist tries to appeal to both the libertarian - the less government intervention, the better off society will be-and the paternalist-a liberal who believes there is a paternal role for government to play, particularly in healthcare.

Two former colleagues at the University of Chicago, Richard Thaler of the Graduate School of Business and Cass Sunstein of the Law School, proposed the idea of libertarian paternalism - a compromise between a conservative and liberal perspective. Perhaps you can call this a paternal nudge in the healthy direction, while leaving ultimate responsibility to the individual.

An example to demonstrate this strategy is focused on middle-aged adults, though given the topic it is quite relevant to older adults. Researchers targeted a group of 480 university employees prior to the annual influenza vaccination season (Lehman et al., 2016). Participants were randomly assigned to a control group that received an email message that free flu shots were available at the campus health center, with a link for making an appointment; or to a treatment group that received an email that they had been scheduled for a flu shot at a specified time, with a link for canceling or changing the appointment.

The control group had to take the initiative to opt in for a flu shot, and $33 \%$ did. The treatment group was already opted in, and had to take the initiative to opt out. In this group, $45 \%$ received a flu shot.

The libertarian is pleased because in both instances the initiative remains with the individual. The paternal liberal is pleased because the default position, where one does not have to go to the trouble of opting out, is the healthier alternative and likely to produce the higher participation rate.

Another example? Automatic enrollment in an employer retirement plan that requires the employee to opt out, versus the more typical policy to opt into a retirement plan. This policy change increased participation rates from $50 \%$ in the traditional must-opt-in plan, to 90\% - do nothing and you have opted in (Pew's 2017 Survey of Workers, September 20, 2017).

retirement choices. Healthy People initiatives should just nudge-Thaler and Sunstein's term-people and organizations in the right direction without excessive intrusion and cost.

If you are interested in the Healthy People initiatives, you can access information by going to www.health.gov/healthypeople/state/toolkit. One last comment. I will end this section by briefly getting back to the question raised at the beginning of this chapter: "Does establishing federal goals help to promote healthy aging?" and give you a succinct answer: Not if you are only setting goals and monitoring.

\section{AGING, HEALTH, SOCIAL, AND MEDICAL TRENDS}

It has been almost obligatory for 40 years to begin a gerontological book or article with comments about the rapid aging of society. The social analyst Ann Roberson labeled this phenomenon "apocalyptic demography," in which the escalating increases in the number of older adults will portend social and economic crises. About 20 years ago, 
we began to see two slight variations of this apocalyptic ritual: Many published works began with comments warning about the aging of the aged, and an additional spate of writings were on the coming onslaught of aging baby boomers.

Today, with the vanguard of baby boomers and the very older old receiving considerable media attention for different reasons, both ends of the older age spectrum command our full attention. The robust baby boomers-cum-gerontology boomers make it obvious to all but the most ageist that the vitality of aging persons can remain strong. The stereotype of aging as merely physical and mental deterioration has been convincingly challenged. Also, an increasing number of boomers are tapping into Social Security and Medicare, and this deserves our attention as well.

At the other end of the age spectrum, among persons age 85 and older, the growth in the percentage of the very old begins to startle-about a $40 \%$ growth per decade. In 1980, there were 2.2 million Americans aged 85 and over; in 1990, about 3 million; in 2000 , around 4.3 million; and in 2010, about 6 million. While the rate of increase slows thereafter, those age 85 and older are expected to reach 14.6 million by 2040 (Administration for Community Living \& Administration on Aging, 2018). The oldest of the old require considerable assistance at a not insignificant cost to society.

Along with the increasing breadth of the age span of Americans comes increasing complexity. Fifty-year-olds are eligible for membership in AARP (formerly the American Association of Retired Persons-however, too many members were not retired with the lowering of the membership eligibility age to 50, hence the use of the acronym only), and they are quite different from 70-year-olds, who in turn are significantly different from 90-year-olds. Moreover, 90-year-olds are different from one another. A few of them are pumping iron and throwing away their canes, whereas others are waiting to die.

\section{Is Health Promotion Cost-Effective?}

What aging Americans have in common, be they 50 or 90 , robust or frail, is a future with an intensified demand for medical care (euphemistically referred to in America as healthcare) and the ongoing escalation of medical care costs. Driving these demands and costs are the increasing number of aging persons with both chronic and acute medical conditions and an expensive, high-tech, acute care-oriented medical system.

Some argue that the solution to rising healthcare costs is to encourage health promotion, disease prevention, and chronic disease management. This may be true but the evidence is scant and not yet encouraging. Health promotion advocates often fail to consider that prevention, promotion, and management entail:

- Substantial costs in the attempt to screen and educate everyone, along with subsidizing subsequent interventions; and

- If health promotion/disease prevention programs work, healthier individuals will live longer on a taxpayer-supported Medicare program, only to die of other costly medical conditions.

Perhaps the skeptics of health promotion's ability to lower healthcare costs support the philosopher Woody Allen's contention: Death is the best way to cut down on expenses.

\section{A Multifaceted Approach}

Yes to health promotion! The media has taken a stand, allocating considerable time and space to the merits of promoting good health practices to improve quality of life and 
realize medical care cost savings. Joining the media are the health professions, which have proclaimed its importance in the education and training of students; the business community, which has firmly supported a wellness approach for employees; and individual people, who often discuss their attempts at health promotion, both successful and otherwise, with relatives and friends.

If the media, the health professions, the business community, and individual people are willing to hop on the wellness train, the government has been reluctant to subsidize the fuel. Federal and state governments have been concerned more about dealing with rising expenditures than with new disease prevention, health promotion, and disease management initiatives that require additional funding.

Government can share the blame. Health professionals provide mostly lip service to promoting health because they are not reimbursed for it. Health science instructors provide only a modicum of health promotion instruction and training, and experience in applying it is the exception rather than the rule. The business community allocates resources to worksite wellness, but has stopped short of focusing on those who need it most-older and more sedentary employees.

Last but not least, too many people have spent not only more time and money on health promotion, but also more time and money at fast-food restaurants, eating larger portions of food with higher fat, sugar, and sodium content; and on computers, in front of which they sit, unhealthily immobile, for an increasing number of hours. And even though it is true that a smartphone is portable, walking while staring at it the same time is dangerous. (Particularly when you are walking across the street, which seems to be a pastime with students on my university campus.)

\section{Population Growth Over Age 65}

All but the most uninformed know that the average age of the American population has been increasing dramatically. In just 16 years, the U.S. Census Bureau (Federal Interagency Forum on Aging-Related Statistics, 2016) reported that the number of Americans age 65+ increased from 35 million (12.4\%) in 2000 to 49.2 million (15.2\%) in 2016. From a long-term perspective, almost two-thirds of the growth in the number of Americans age $65+$ will take place after 2010 and before 2060 (Figure 1.1). The percentage of the population age 65 and over is projected to reach $20 \%$ in 2030.

FIGURE 1.1 Population age 65 and over and age 85 and over, selected years, 1900-2014, and projected years, 2020-2060.

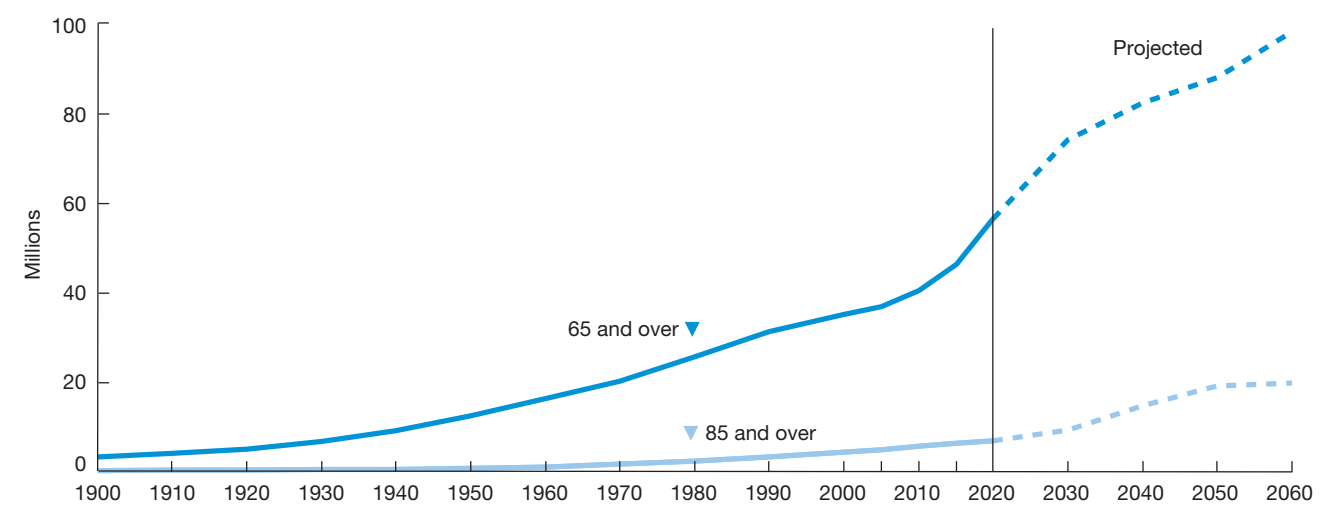

Source: Federal Interagency Forum on Aging-Related Statistics. (2016). Older Americans 2016: Key indicators of well-being. Washington, DC: U.S. Government Publishing Office. Retrieved from https://agingstats.gov/docs/ LatestReport/Older-Americans-2016-Key-Indicators-of-WellBeing.pdf 


\section{TABLE 1.2 BECOMING AN AGE RECTANGLE}

YEAR

1900

1980

2030
POPULATION UNDER AGE 18

$40 \%$

$28 \%$

$20 \%$
POPULATION OVER AGE 65

$4 \%$

$11 \%$

$20 \%$

The percentages in Table 1.2 show why the population "age pyramid" - a few older adults at the top and many children at the bottom-is rapidly becoming an "age rectangle."

\section{The Baby Boomers}

The baby boomers are the 76 million persons who were born in the United States between 1946 and 1964. Most were conceived when the millions of soldiers, sailors, and marines returned home from World War II and created a surge in the number of births that started quickly-there were fewer than 2.8 million births in 1945 but more than 3.4 million in 1946-and lasted 19 years.

The boomers challenged U.S. hospital capacity when they were born, the adequacy of the public school system a few years later, society in general when they reached draft age and spurned the politicians who were intent on expanding the Vietnam War, and still later the sufficiency of available housing for raising their families.

The baby boomers' place in history, as they begin to dominate the old age segment of it, is still unclear. Will they be known as the spoiled descendants of the Greatest Generation or as pioneers in social reform and civil rights? Regardless, their impact on society as older persons will raise a troublesome question, one posed by the Beatles in a (paraphrased) song lyric that asks society if it will "still need us when we're 64."

If the Beatles had been more knowledgeable about aging, they would have substituted 84 for 64, as it more accurately represents a threshold to frailty. (As far as they were concerned, 64 was the same as 84: too old to differentiate.) Hopefully, we will be able to answer this question in the affirmative by the time the first boomers reach age 84 in 2030.

By 2010, the number of Americans between the ages of 45 and 64 (roughly the boomers at that time) was about twice that of those age 65 and over: roughly 79 million versus 39 million. And those boomers were bringing into retirement not only their large numbers and a history of advocacy, but also a powerful interest in, and impact on, the integrity of the Social Security and Medicare programs and the adequacy of long-term care alternatives. Their future influence on society is likely to be dramatic and widespread as they become retirees in increasing numbers.

As eloquently stated by Frank Whittington, who at the time was director of Georgia State's Gerontology Center (and paraphrased here),

On January 2, 2008, shortly after 9 a.m., a simple bureaucratic event was the harbinger of a fundamental change in American society. Kathleen Casey-Kirschling-the first baby boomer, who had been born one second after midnight on January 1, 1946-walked into the local office of the Social Security 
Administration and applied for retirement benefits. She celebrated her 62nd birthday on New Year's Day and applied for early Social Security benefits at her first opportunity. Over the next couple of decades over 70 million of her peers will follow suit. We must not doubt that when Kathleen Casey-Kirschling strode up to the counter to ask for her benefits, all of our lives had begun to change.

As boomers retire, they will make enormous demands on both the Social Security and Medicare programs, which, at the same time, will be supported by a shrinking taxpaying workforce. By the time the last boomer turns 65 in the year 2029, the retirees drawing Social Security and Medicare benefits will account for one in five Americans.

Will boomers be healthier than today's cohort of older adults? Death rates for heart disease and stroke continue to decline, while longevity continues to increase. But diabetes (affecting 20\% of boomers and rising), chronic lower respiratory disease, high cholesterol, and hypertension were higher compared to a comparable age cohort two decades earlier. Much of this has to do with the increase in overweight and obesity. Advances in medicine and medical technology may enable boomers to live longer and possibly sicker, according to data analyzed from the National Health and Nutrition Examination Survey.

\section{The Older Old}

The older population itself is getting older. The percentage of persons age 85 and over is growing faster than any other age group. As noted earlier, there was a $36 \%$ increase among Americans 85 and over from 1980 to 1990 (from 2.2 million to 3 million), a 43\% increase from 1990 to 2000 (from 3 million to 4.3 million), and a 40\% increase from 2000 to 2010 (from 4.3 million to about 6 million). This growth slows only slightly over the next half-century, and is projected to reach 20 million over age 85 by 2060 .

This demographic trend is significant for two reasons. On the positive side, the rapid growth of this segment of the population has made what was previously an age level rarely attained into an increasingly common stage of the life cycle. Moreover, the percentage of older adults who reach age 75 and beyond and report good or excellent health is $66 \%$.

One analyst reported that 70-year-olds are more like the 60-year-olds of previous generations (Trafford, 2000). Older adults have an even better perception about themselves. The National Council on Aging (2002) together with the Harris National Survey reported that $51 \%$ of persons between the ages of 65 and 74 and 33\% of persons age 75 and over perceive themselves as middle-aged or younger! This certainly is evidence that many older adults are redefining old age as beginning later in the life cycle.

On the challenging side, for both families and society, is the fact that the ability of this age group to function fully independently is significantly less than for the younger old.

Activities of daily living (ADLs) make up the standard for assessing functionality and refer to bathing, dressing, eating, transferring, toileting, and, the last being the most common ADL problem, walking. Instrumental activities of daily living (IADLs) refer to the ability to perform more complex activities such as home management, money management, meal preparation, making a phone call, and, the last being the most common IADL problem, grocery shopping. In addition to Figure 1.2 showing that IADL limitations are more common than ADL limitations, two other conclusions can be drawn: 
1. Age $75+$ is three times more vulnerable to dependency than the adjoining age category of 65 to 74 (and more than three times likely to be institutionalized), and

2. Age category 65 to 74 is not significantly different from the younger adult age categories.

Therefore, when it comes to anticipating caregiving challenges to both family and society, and the need for additional resources, age 75- or 80 or 85 -is a much more significant cutoff point for analysis than the traditional age 65+ entry into old age.

\section{Disability and Chronic Conditions}

Disability is defined by the U.S. Census Bureau as difficulty with hearing, vision, cognition, ambulation, self-care, or independent living. In 2015, 35\% of persons age 65 and over had some type of disability, with ambulation difficulty the most likely (23\%). Some of the difficulties presented in Table 1.3 may be considered manageable by the older adult, while others require personal assistance.

F I G URE 1 . 2 Percentage of adults with activity limitations, by age group and type of limitation.

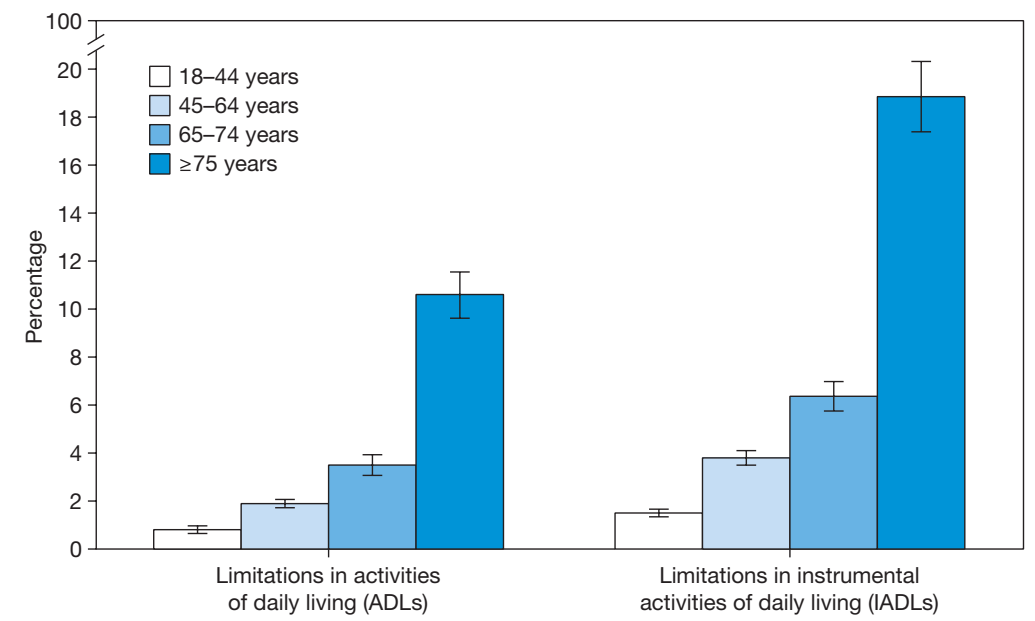

Source: Centers for Disease Control and Prevention. (2016). QuickStats: Percentage of adults with activity limitations, by age group and type of limitation - National Health Interview Survey, United States, 2014. Morbidity and Mortality Weekly Report, 65, 14. doi:10.15585/mmwr.mm6501a6

\section{TABLE 1.3 PERCENTAGE OF PERSONS AGE 65+ WITH A DISABILITY, 2015}

$\begin{array}{lr}\text { Independent living difficulty } & 15 \% \\ \text { Self-care difficulty } & 8 \% \\ \text { Ambulatory difficulty } & 23 \% \\ \text { Cognitive difficulty } & 9 \% \\ \text { Vision difficulty } & 7 \% \\ \text { Hearing difficulty } & 15 \% \\ \text { Any disability } & 35 \%\end{array}$

Source: U.S. Census Bureau. (2015). American Community Survey: Older Americans with a disability. Washington, DC: U.S. Department of Commerce. 
FIGURE 1.3 Percentage of people age 65 and over who reported having selected chronic health conditions, by sex, 2013-2014.

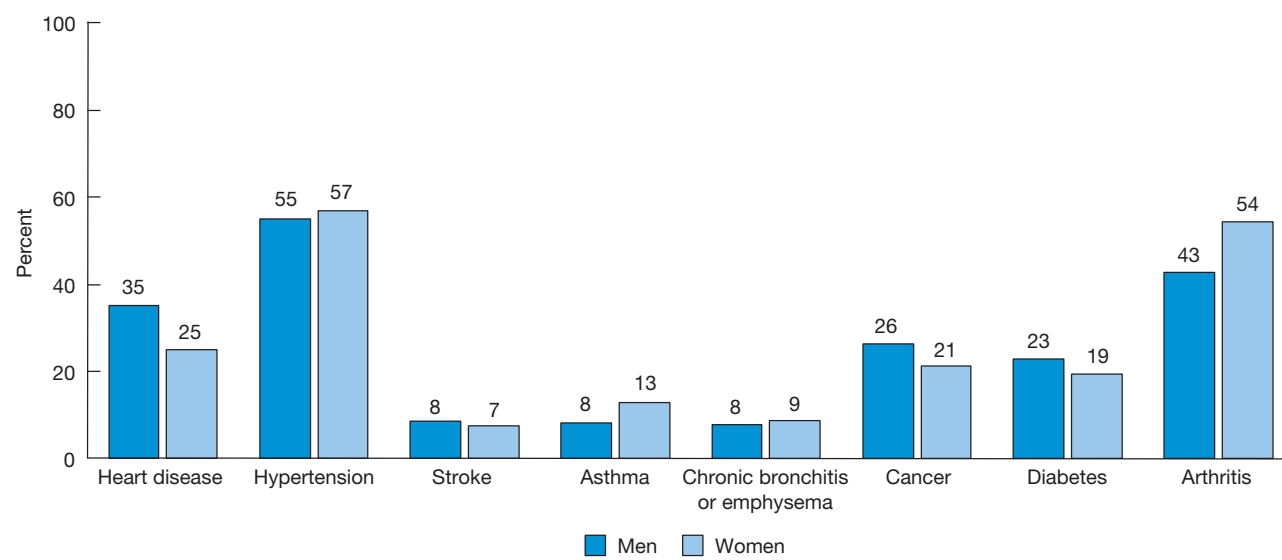

Source: Federal Interagency Forum on Aging-Related Statistics. (2016). Older Americans 2016: Key indicators of well-being. Washington, DC: U.S. Government Publishing Office. Retrieved from https://agingstats.gov/docs/ LatestReport/Older-Americans-2016-Key-Indicators-of-WellBeing.pdf

The leading chronic conditions among older adults are listed in Figure 1.3. The prevalence of each condition increases in old age, and persons over age 85 often have multiple chronic conditions. The leading chronic conditions are hypertension, arthritis, heart disease, cancer, and diabetes. Women report higher levels of asthma, arthritis, and hypertension; men report higher levels of heart disease, cancer, and diabetes.

Although chronic conditions and functional limitations increase with age, disability rates for older Americans have been declining. In 1982, the disabled older population in the United States totaled 6.4 million. If the 1982 rate had continued, the number of disabled would have climbed to about 9.3 million in 1999. Instead, it rose to only 7 million-less than a quarter of the increase that might have been expected. More recently, the overall percentage of Americans age 65+ with a disability declined between 2013 and 2015.

Another hopeful research outcome in disability trends is the conclusion that among the very old, disability decline slows significantly. As more people today are living into their 90s and beyond (which is the fastest-growing age segment of society in developed countries), researchers have found that the percentage who are independent changed less than expected between the ages of 92 and 100 .

For example, 39\% of 92-year-old Danish adults were able to care for themselves, and the same was true of 33\% of those who lived to the age of 100 (Christensen, McGue, Petersen, Jeune, \& Vaupel, 2008). In general, loss of independence among the very old appears to occur close to the end of life and is not significantly more severe or costly for the 100-year-old than for the 90-year-old.

\section{Centenarians}

A USA Today / ABC News poll reported that only 25\% of Americans want to live to be 100 or older. (Do you?) The majority of Americans are concerned that they will become disabled and a burden to their families. And yet many Americans are fascinated by the idea of becoming a centenarian.

In 2015, the census showed that there were 77,000 people who were 100 years or older, an increase of almost 10,000 people from just the prior 2 years. Census projections forecast that there will be eight times that many by the year 2050, when some baby boomers begin reaching age 100 . 
For every 100 centenarian women, there are only 20.7 centenarian men. Thus, the oldest person alive during any particular year is typically a woman. According to the Guinness Book of World Records (www.guinnessworldrecords.com), a French woman, Jeanne-Louise Calment, has lived the longest, reaching 122 years before she died in 1997. She stated: "I just kept getting older and couldn't help it."

(Maybe she did help it. In 2019, skeptics argued that her daughter, Yvonne Calment, took over her identity to avoid estate taxes. If that is the case, Yvonne died at age 99 and the American Sarah Knauss took over as longest-lived, having died at age 119.)

On June 9, 2005, the world's oldest living married couple had an aggregate age of 205 years. Magda Brown, age 100, attributed her 74-year union to Herbert Brown, age 105, to her taking the lead ("I am the strong one") and his following ("He is the easy-going one"). Apparently, Herbert is more than just easy going: He survived the Nazi concentration camp at Dachau.

\section{Supercentenarians}

In 2005, the oldest living documented person at that time (able to provide original proof of birth) was a Dutch woman, Hendrikje van Andel-Schipper, who reached 115 years and attributed her longevity to eating a piece of herring every day. In 2015, Jeralean Talley was the longest-lived person and also reached 115 years. She challenged the prior advice and attributed her long life to eating pigs' ears and feet. After Ms. Talley died, a New Yorker, Susannah Mushatt Jones, yet again 115 years old, became the longest-lived person and attributed her longevity in part to bacon.

As of this writing, therefore, pork seems to be a leading contributor to becoming a supercentenarian - 110 years of age or older. On the Gerontology Wiki website (gerontology. wikia.org/wiki/The_110_Club) in 2018 there were 257 supercentenarians with validated birth and death rates who ever lived for any length of time in the United States, seven of whom are currently living in the United States.

Another supercentenarian, Misao Okawa, just left the ranks after being a widow for more than 80 years. Despite (or because of?) her lengthy widowhood, she offered this comment when asked about how she felt about the past 117 years: "It seemed rather short."

\section{Super-Duper-Centenarians}

One scientist is not content with being a mere supercentenarian. Aubrey de Grey is a controversial practitioner of biogerontology, which focuses on the biology, physiology, and genetics of aging. He believes that the first person who will live to be 1,000 might be age 60 today. (A more modest and credible assertion by Christensen, Doblhammer, Rau, and Vaupel [2009] is that $50 \%$ of women born today in the most-developed countries will celebrate their 100th birthday.)

Although de Grey's ideas are far from the scientific mainstream, he has inspired considerable interest in his theories, having been invited to deliver dozens of presentations in the United States. This interest may have been stimulated in part by his offer of a $\$ 20,000$ cash prize for anyone who can disprove the scientific basis of his theories, as determined by a review panel of independent molecular biologists. His provocative ideas on increased longevity range from stem cells that can regrow diseased tissue to implanting bacteria to clean up waste that builds up inside cells.

If the Englishman turns out to be right, supercentenarians will have to take a back seat to thousandarians (granderians? millennerians?). 


\section{Life Expectancy}

The life expectancy of Americans in 2017 was 78.6 years. This was notable because the prior 3 years all reported higher life expectancies, which had peaked at 78.9 in 2014 . This slight downward slump was notable because over the past century, life expectancy had rarely declined or even plateaued in America. In fact, as a result of advances in sanitation, medicine, and health behaviors (particularly smoking cessation), American life expectancy had steadily climbed since 1900 .

Some attribute this recent downward trend as perhaps temporary and due to an increase in drug overdoses, drug deaths, and suicides, particularly among those between the ages of 25 and 44 (Katz \& Sanger-Katz, 2018). Others note that the United States has been falling behind other countries in life expectancy for quite some time, and now trailed 49 other countries, with 30 of these countries having a life expectancy over age 80. Increases in obesity, and the related conditions of hypertension and diabetes, the opioid crisis, or other events may foster this trend, while continued advances in medicine in the United States may reverse it.

There is also a gender longevity gap in the United States. The life expectancy of men in 2017 was 76.1 and for women it was 81.1. This 5-year gap was the smallest recorded since 1946. The population of men ages 85 to 94 grew by nearly half, whereas the number of women in the same age group increased by about a fifth. Medical experts speculate that women are working harder, smoking more, and undergoing more stress. The disparity between Blacks and Whites is also declining, with the gap between Black and White men being 6 years and the gap for women 4 years.

Heart disease continues to be the leading cause of death in 2016 (see Table 1.4), but during the prior decade, the gap between heart disease and cancer narrowed. Also during this time, respiratory diseases and Alzheimer's disease rose in the rankings.

\section{TABLE 1.4 TEN LEADING CAUSES OF DEATH AMONG OLDER ADULTS AGE 65+} IN 2016

\section{CAUSES OF DEATH}

1. Heart disease

2. Cancer

3. Chronic lower respiratory diseases

4. Unintentional injury (accidents)

5. Stroke

6. Alzheimer's disease

7. Diabetes

8. Influenza and pneumonia

9. Kidney disease

10. Suicide

\section{NUMBER OF DEATHS}

614,000

592,000

147,000

136,000

133,000

94,000

76,000

55,000

48,000

43,000 
The Centers for Disease Control and Prevention (CDC) notes that the current system of relying on death certificates misses the complexity of dying for many older people and underestimates the impact of Alzheimer's disease. The death certificate lists the most immediate cause of death, while Alzheimer's disease may have been a major contributor to the person dying from pneumonia (perhaps with food going down the windpipe) or from infections and other problems.

\section{Hospital Stays and Physician Visits}

The average length of a hospital stay for an older patient continues to decline, from more than 12 days in 1964, to 8.5 days in 1986, to 6.5 days in 1996, to 5 days in 1999, to 4.6 days in 2007. As a percentage of overall Medicare costs, hospital expenditures declined from $32 \%$ to $24 \%$ between 1982 and 2008, and instead of being the major cost driver, it is only two-thirds of the amount Medicare spends on physician/outpatient costs.

Although quickening hospital discharges over the past few decades affect all age groups, the growing number of older adults in the United States results in a higher percentage of older patients in the hospital. Older adults accounted for $20 \%$ of hospital stays and used one-third of the total days of hospital care in 1970; by 2000, they accounted for $40 \%$ of hospital stays and almost one-half of the days of hospital care (Hall \& Owings, 2002).

Older persons had more than seven office visits with their doctors in 2009, compared to persons aged 45 to 65 , who averaged fewer than four office visits. It is estimated that older patients occupy $50 \%$ of the time of healthcare practitioners, and it is predicted with near certainty that the percentage of time that healthcare practitioners spend with older patients will continue to increase.

\section{Medication Use}

Medicare expenditures on medications for noninstitutionalized elders increased at an astounding rate for many years (double-digit increases from 1994 to 2001) but have risen more slowly over the past decade. These expenditures constitute $15 \%$ of overall healthcare spending. A primary reason for the slowing of rising medication costs has been an expansion in the availability of low-cost generic drugs, which has increased to $80 \%$ of all dispensed prescriptions. This trend toward generic drugs is due to many expensive, brand-name medications coming off patent protection.

This cost saving, however, has been offset by three factors: (a) The escalating costs for brand-name drugs still in use, with costs rising 62\% between 2011 and 2015, with the continued demand for these expensive brand-name drugs being fueled by advertising on television. (b) There has been an increase, though slower, in the price of generic drug costs as well. (c) The pharmaceutical industry has maintained profitability in an era of widespread use of generic drugs by the application of lobbying pressure to Congress: As part of the passage of Medicare Part D in 2006, the Medicare program was banned from negotiating future reductions in drug prices.

While overall medication expenditures have risen more slowly lately, medication usage and costs are highly correlated with age. Older adults constitute about $15 \%$ of the population but consume $34 \%$ of all prescription drugs and $40 \%$ of over-the-counter drugs. A nationally representative sample of community-residing older persons, aged 57 to 85 years, for instance, revealed that at least one prescription medication was used by $81 \%$ of the sample during the prior month, at least one over-the-counter medication by $42 \%$, and at least one dietary supplement by $49 \%$. Also, at least five prescription medications were being used concurrently by $29 \%$ of the sample (Qato et al., 2008). By 
2012 , the use of five or more prescription drugs increased to $39 \%$ of those over 65 years of age (Kantor, Rehm, Haas, Chan, \& Giovannuci, 2015).

\section{Health Habits}

On the brighter side, the health habits of older adults may, on balance, be slightly superior to those of younger adults. People age 65 and over, for instance, are less likely to smoke, drink alcohol, or report high stress. They eat more sensibly than do younger adults, are as likely to walk for exercise, and are more likely to check their blood pressure regularly. Older adults continue to increase their rate of participation in medical screenings and immunizations, and are consistent with the use of seatbelts.

On the darker side, older adults are more likely to be sedentary or malnourished. And their advantage in being less stressed may be merely the result of less awareness of, or less willingness to report, stress. The lower percentage of smokers may be due in part to the fact that smokers are more likely to die before age 65. Also, when older adults engage in risk behaviors such as excessive alcohol consumption, sedentary behavior, poor nutrition, and failure to use seatbelts, their vulnerability to morbidity and mortality is greater.

To put things in perspective, though, few adults in the United States, young or old, live a comprehensively healthy lifestyle. National data reveal that only $3 \%$ of the population engage in all four of the following lifestyle choices: nonsmoking, healthy weight, five fruit and vegetable servings per day, and regular physical activity (Reeves \& Rafferty, 2005). Among older adults, one-third do not get any leisure-time physical activity, two-thirds do not eat five servings of fruit or vegetables a day, and one-fifth are 30 pounds or more overweight.

\section{Perceptions of Health}

Despite stereotypes to the contrary, most people who are older tend to view their health positively (Federal Interagency Forum on Aging-Related Statistics, 2016). Seventy-eight percent of older adults, age 65 and over, rate their health as being good, very good, or excellent. Among those age 85 and over, this percentage declines to $68 \%$ who report good, very good, or excellent health. (Still a lot higher than you would expect, right?) This percentage further declines to $65 \%$ among Black or Hispanic older adults age 65 and older, and to $56 \%$ among those without a high school diploma.

\section{Volunteering}

Many older adults are active and productive, and some choose to engage in volunteer opportunities. In any given year, almost one-fifth of older Americans engage in unpaid volunteer work for organizations such as churches, schools, or civic organizations. In addition, an unknown percentage of older adults do other types of volunteer work, such as helping family and friends who are sick or disabled, or assisting with the care of grandchildren.

Surprisingly, those who continue to work after age 65 are not less likely to volunteer than those older adults who retire (Caro \& Morris, 2001). Researchers believe that the potential for increasing volunteerism among retired older adults is significant, and that "in the period immediately after retirement there is a heightened receptivity to volunteerism" (Caro \& Morris, 2001, p. 349). 


\section{Marital Status}

Older men are much more likely to be married, $70 \%$ versus $46 \%$, and much less likely to be widowed, $11 \%$ versus $33 \%$, than older women (see Figure 1.4 ). In absolute numbers, there were more than three times as many widows ( 8.8 million) as widowers (2.6 million). Divorced or separated older adults represented 15\% (steadily increasing since 1980), and single adults $5 \%$ of the population (also increasing). All of these categories will increase in the future with the expansion of the boomers among the old, and their greater acceptance of divorce, separation, and a single lifestyle.

Most women (54\%) should expect to spend all or part of their later years without a husband. Are most older women preparing for this, or just dealing with the consequences after it happens?

Not examined in Figure 1.4 is cohabitation, which increased 75\% between 2007 and 2016 (Pew Research Center Report, 2017). Whether cohabitation is taking the place of, or in addition to, marriage, has not been determined.

\section{Work}

The labor force participation rate, that is, the percentage of a population that is in the labor force, of older men declined from 1960 through 1995 and then began to rise among men age 65 and over (see Figure 1.5). The 35-year decline may have been due to some combination of factors such as mandatory retirement policies, fewer work opportunities, age discrimination, declining health, or desire for more leisure time. The rise of labor force participation for older men since 1995 may be due to the opposite of these factors-fewer mandatory retirement policies, more opportunities for older workers, less age discrimination, improved health, or desire for more income or purposeful activities.

The U.S. Bureau of Labor Statistics reported that $60 \%$ of older respondents stated financial factors-making money or earning benefits-were a primary influence in choosing to remain in the work force. Thirty-six percent stated they primarily liked

FIGURE 1.4 Marital status of persons age 65+, 2017.

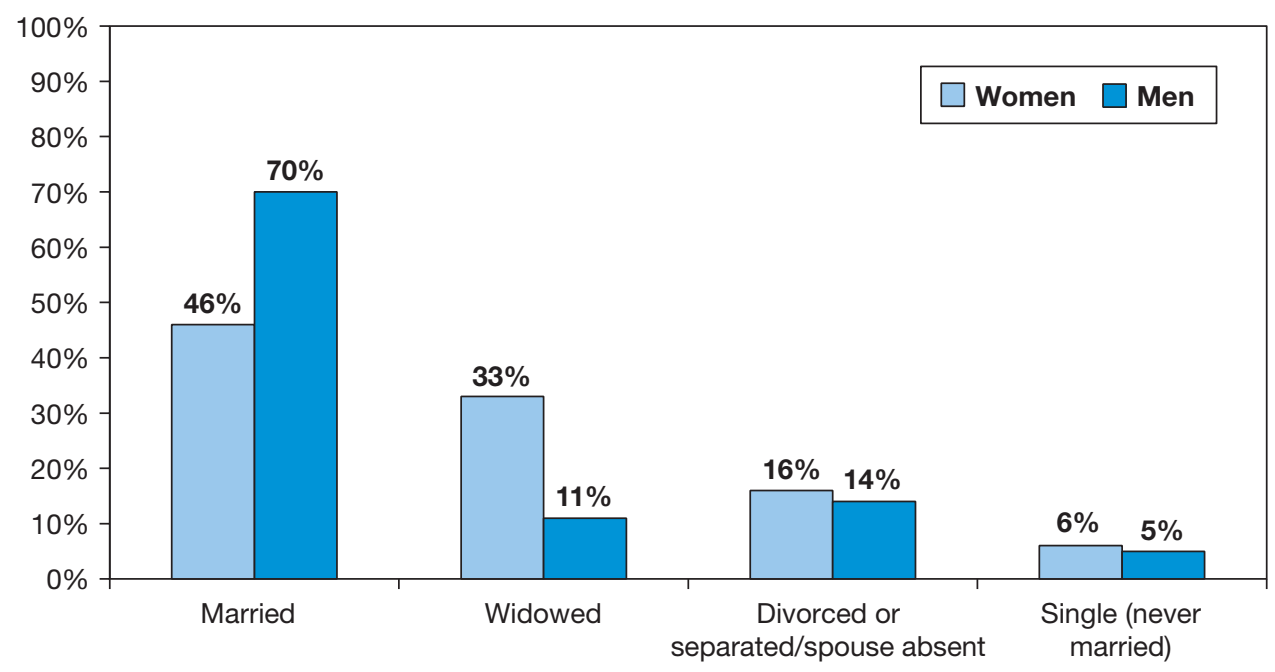

Source: U.S. Census Bureau. (2018, April). Current Population Survey: Annual social and economic supplement. Retrieved from www.acl.gov/sites/default/files/Aging\%20and\%20Disability\%20in\%20America/2017OlderAmeric ansProfile.pdf 
their jobs or wanted to stay involved. Older Americans are healthier and living longer and many need extra money and/or continued purpose.

Labor force participation rates began to rise 10 years earlier for women than for men, around 1985 (see Figure 1.6). While money and continued purpose apply to older women as well, additional factors are an increased opportunity for women to work and the rising expectation that women will work. The difference between the labor force participation of the sexes narrowed for all age groups.

According to a 2012 Gallup survey, 81\% of working people reported that they thought they would work part-time $(63 \%)$ or full-time $(18 \%)$ when they reached retirement age. The part-time predictors were much more likely to state that they would be

FIGURE 1.5 Labor force participation rates (annual averages) of men age 55 and over, by age group, 1963-2015.

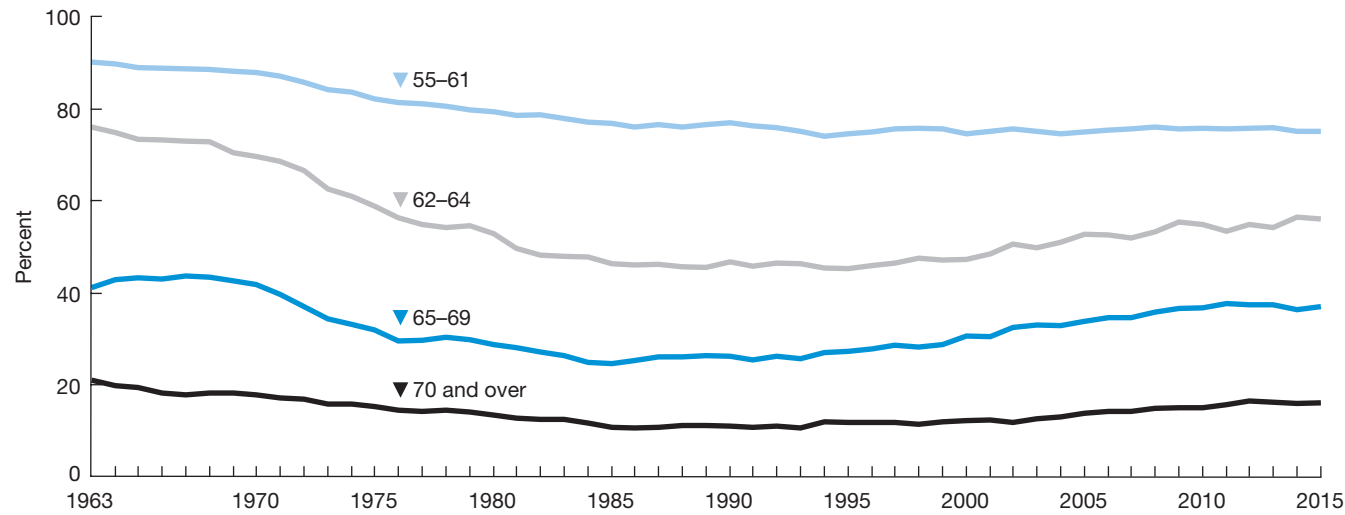

Note: Data for 1994 and later years are not strictly comparable with data for 1993 and earlier years owing to a redesign of survey and methodology of the Current Population Survey. Reference population: These data refer to the civilian noninstitutionalized population.

Source: Data from U.S. Census Bureau. Bureau of Labor Statistics. Current Population Survey.

FIGURE 1.6 Labor force participation rates (annual averages) of women age 55 and over, by age group, 1963-2015.

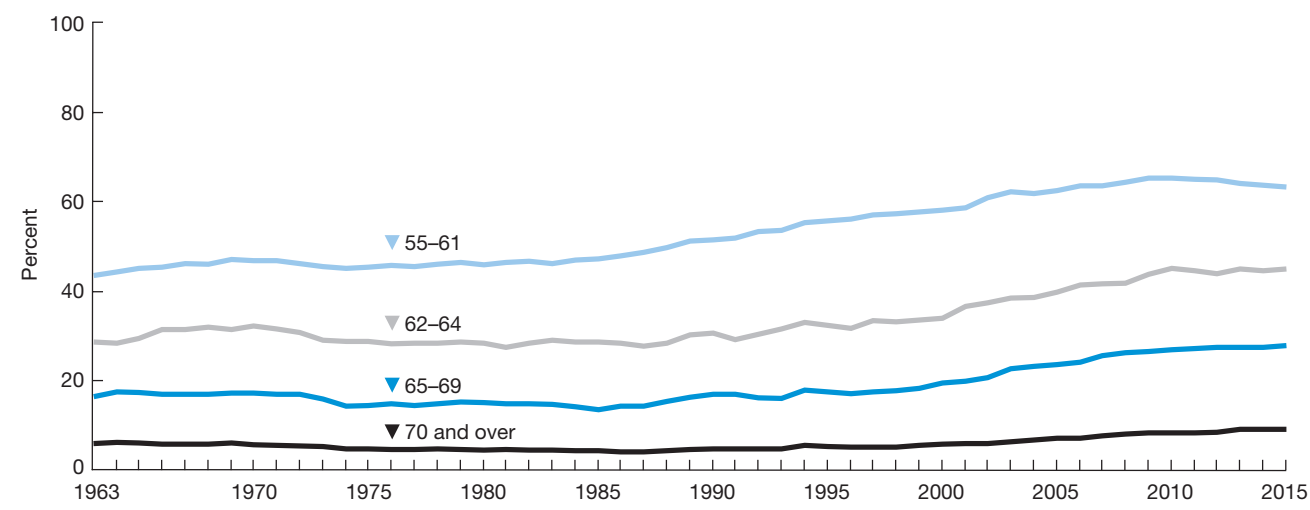

Note: Data for 1994 and later years are not strictly comparable with data for 1993 and earlier years owing to a redesign of survey and methodology of the Current Population Survey.

Reference population: These data refer to the civilian noninstitutionalized population.

Source: Data from U.S. Census Bureau. Bureau of Labor Statistics. Current Population Survey. 
working because they wanted to, while the full-time predictors were more likely to work for financial reasons.

Expecting to work during one's retirement years, obviously, will not be perfectly correlated with actually working, given the challenges of finding a job, sustaining good health, and/or dealing with onerous family caregiving responsibilities. In 2015, 19\% of Americans age 65 and over were in the labor force, including 4.8 million men $(23.4 \%)$ and 4 million women (15.3\%).

With increasing life expectancy, workers can anticipate a longer retirement phase to save for. Complicating matters is that employees are increasingly less able to take advantage of the security and predictability of defined benefit programs (i.e., traditional, lifetime pensions provided by employers), instead having to rely on defined contribution programs (i.e., do-it-yourself retirement savings plans that are subject to the whims of the stock market).

Labor force participation among older adults in the United States is considerably higher than that in most other countries, including France, Germany, Italy, Sweden, United Kingdom, and Canada, although it is lower than the rate in Japan.

\section{Educational Status}

Between 1965 and 2015, the percentage of older persons who had completed high school increased from $24 \%$ to $84 \%$ (Figure 1.7). In 1965, only $5 \%$ had at least a bachelor's degree or more, while in 2015 that figure rose to $27 \%$. When the last baby boomer reaches age 65 (replacing most of the current cohort of older adults), these percentages increase to $89 \%$ high school graduates and $36 \%$ - and counting - college graduates.

Why "and counting?" If Nola Ochs and Phyllis Turner are role models, boomers have plenty of time to further increase their college graduation rate. Nola Ochs got her undergraduate degree from Fort Hays State University in Kansas in 2007 at the age of 95. Nola was not the only nonagenarian that year with such an impressive educational achievement. Phyllis Turner, at age 94, received her master's degree in medical science at the University of Adelaide in Australia. Not many boomers are likely to be discouraged from attending college because of their age.

FIGURE 1.7 Educational attainment of the population age 65 and over, selected years 1965-2015.

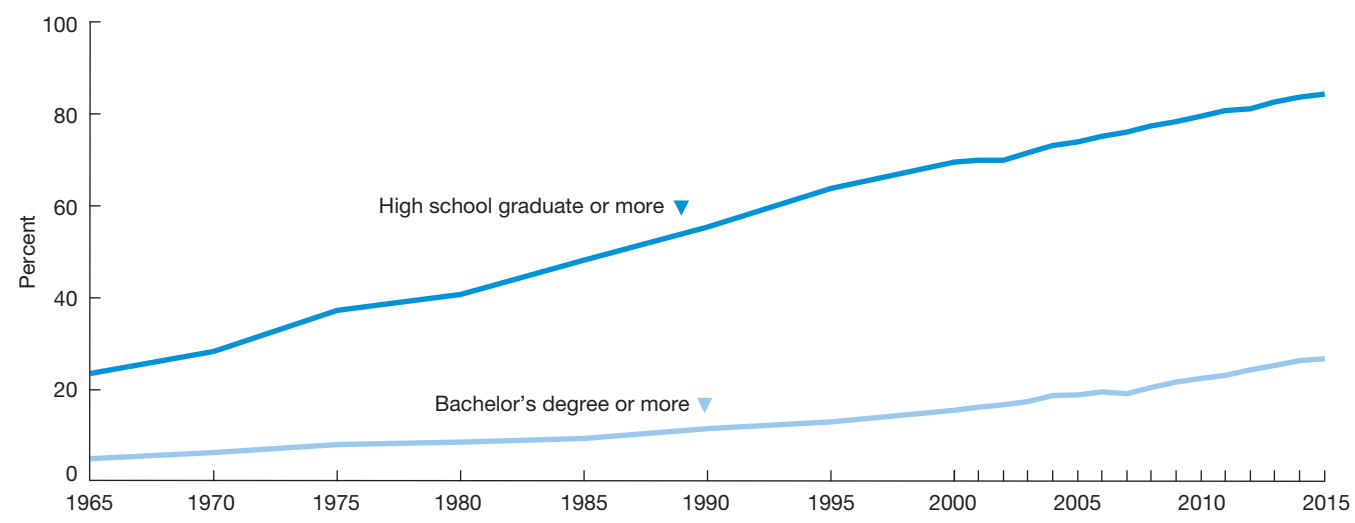

Note: A single question that asks for the highest grade or degree completed is now used to determine educational attainment. Prior to 1995, educational attainment was measured using data on years of school completed. Reference population: These data refer to the civilian noninstitutionalized population.

Source: Data from U.S. Census Bureau. (2016). Current Population Survey: Annual social and economic supplement. Washington, DC: U.S. Department of Commerce. 
In 2010, older men had attained two-thirds of the bachelor's degrees, but if current trends hold, this percentage will soon be substantially reversed. Women have constituted about $57 \%$ of college matriculation for several years now.

The Sloan Center on Aging and Work at Boston College published a fact sheet in 2012 (www.bc.edu/agingandwork) that noted an important fact about the impact of education on older adults who want to continue working. The unemployment rate of workers age 65 or older who had completed 4 or more years of college was only one-half that of older workers who had not completed high school.

Unfortunately, the percentage of older adults who had completed high school varied considerably by race and ethnic origin. In 2015, 89\% of non-Hispanic Whites and $74 \%$ of older Asians age 65 and over had completed high school, versus $75 \%$ of older Blacks and 54\% of older Hispanics completing high school (see Figure 1.8). Regarding attainment of at least a bachelor's degree, 34\% of older Asians had accomplished this and $29 \%$ of older non-Hispanic Whites, versus $17 \%$ and $12 \%$, respectively, for older Blacks and Hispanics.

By 2007, there were more than 400 lifelong learning programs targeted toward older adults in the United States and Canada, almost all of them linked with colleges and universities and many of them loosely associated with Road Scholar (formerly Elderhostel, then Exploritas) or the Osher Lifelong Learning Institutes, funded by the Bernard Osher Foundation. There were also a variety of other lifelong learning opportunities, such as the Adventures in Learning programs at Shepherd's Centers, the educational programs at OASIS Centers, and other innovative educational options at community colleges, community centers, art museums, and hospitals.

As the educational level of older adults continues to rise, this may well correlate with an increase in their interest in seeking out health information and engaging in health-promoting activities in their communities.

FIGURE 1.8 Educational attainment of the population age 65 and over, by race and Hispanic origin, 2015.

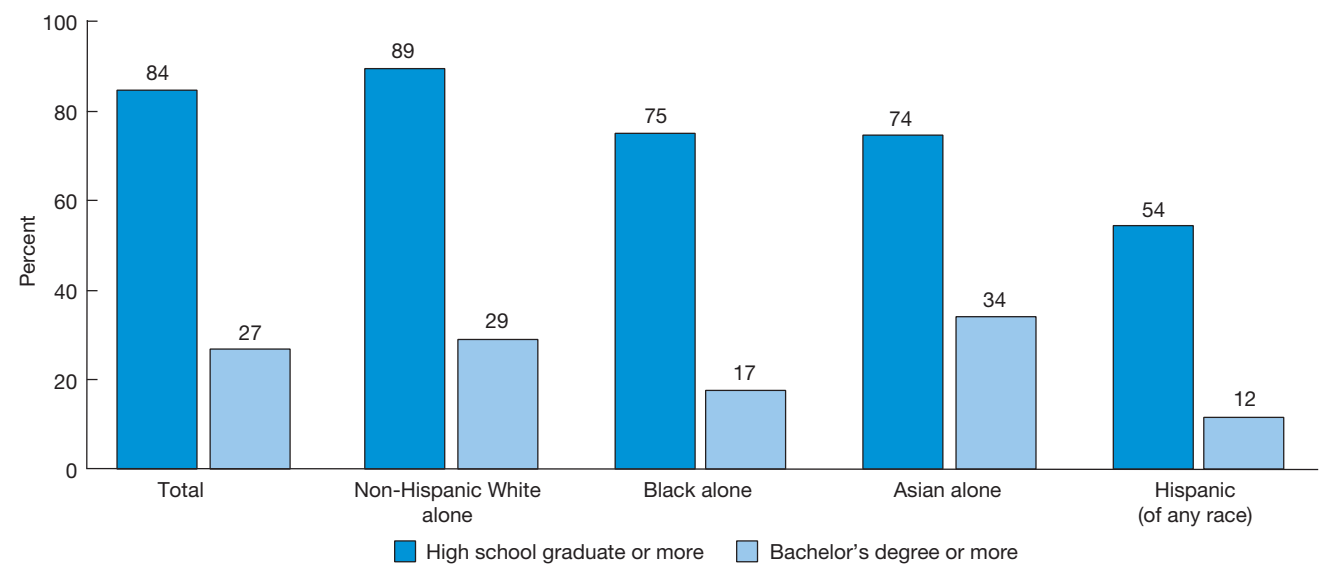

Note: The term "non-Hispanic White alone" is used to refer to people who reported being White and no other race and who are not Hispanic. The term "Black alone" is used to refer to people who reported being Black or African American and no other race, and the term "Asian alone" is used to refer to people who reported only Asian as their race. The use of single-race populations in this chart does not imply that this is the preferred method of presenting or analyzing data. The U.S. Census Bureau uses a variety of approaches.

Reference population: These data refer to the civilian noninstitutionalized population.

Source: Data from U.S. Census Bureau (2016). Current Population Survey: Annual social and economic supplement. Washington, DC: U.S. Department of Commerce. 


\section{Political Power}

The Federal Election Commission reports that older adults are disproportionately likely to vote. In the 2016 presidential election, $71 \%$ of those age $65+$ voted! This compares to $67 \%$ for those ages 45 to $64 ; 59 \%$ for those ages 30 to 44 ; and $46 \%$ for those ages 18 to 29 . These age discrepancies have been consistent for several decades. When AARP speaks, politicians listen!

There are also significant voting differences among older adults, as they are also influenced by socioeconomic class, ethnicity, gender, and religion (Binstock, 2009). Even when they do throw their weight toward one candidate, they don't always get their way. Older voters in the 2008 presidential election were the only age group that gave a majority of their votes to John McCain-to no avail.

Did older McCain voters become more conservative with age? Or did a specific cohort that was always more conservative, remain so? Or did McCain voters just vote for an age peer (McCain was 71 in 2008; Obama was 47)? Unfortunately, only this gerontologist finds these questions interesting. I could not find any research on this topic. What is your opinion, and why?

\section{Internet Access}

A 2012 national survey from the Pew Research Center's Internet and American Life Project reported that more than half - a majority for the first time-of adults ages 65 and older were online. This is due to the tech-savvy baby boomers moving into the age $65+$ ranks. Internet use among those over age 75 was, in contrast, only one-third. By the publication date of this eighth edition of my book, the Internet access gap between younger and older adults will have closed significantly.

Social networking use among Internet users ages 65 and older more than tripled between 2009 (13\%) and $2013(43 \%)$, according to a report from the Pew Internet and American Life Project. The Pew study reported that people younger than age 50 used social networking websites primarily to stay in touch with friends, and people older than age 50 reported that they used them primarily to connect with family, particularly those who live far away. They especially want to see photographs of grandchildren. They also use social networking sites to look up old friends and connect with people who share hobbies.

There are no gender differences in overall computer usage, but engagement with social networking sites is greater among older females than older males. Income and education levels still affect differences in the amount and range of computer usage.

\section{Poverty}

Poverty kills! According to the Brookings Institution, for a cohort of men born before 1950, life expectancy was 14 years shorter among those in the bottom $10 \%$ of earners than among those in the top $10 \%$ of earners.

On a more positive note, the poverty rate among older persons had fallen from $35 \%$ of those age 65 and over in 1969 to $9.3 \%$ in 2016. Without Social Security and cost-of-living increases, this rate would have risen to $50 \%$ over this time period. Instead, the poverty rate for older adults has, seemingly, fallen below the rate for persons age 18 to 64 .

I noted "seemingly," because the declining poverty rate for older adults may be overstated. The U.S. Census Bureau assumes that the costs of food and other necessities 
are lower for older adults and it does not adequately take into account the rising costs of medical care, transportation, and housing. Also, there are hidden poor among the older population who reside in nursing homes or who live with relatives and are not counted in the official census statistics (Hooyman \& Kiyak, 2011).

The Supplemental Poverty Measure is a U.S. Census research tool that considers previously overlooked costs, like out-of-pocket medical expenses for older adults, and estimates the poverty rate of seniors to have been 14.5\% in 2016 instead of the $9.3 \%$ noted earlier. The National Academy of Sciences estimated the poverty rate for older Americans even higher at $19 \%$. Perhaps another estimate could be $33 \%$, which is the percentage of older adults who rely on their Social Security check for $90 \%$ or more of their total income.

The poverty rate is more than twice as high for older Hispanics and Blacks $(17.4 \%$ and $18.7 \%$ ) than for older Whites (7.1\%), and more than $40 \%$ higher for older women (10.7\%) than for older men (7.6\%; Administration for Community Living \& Administration on Aging, 2018). Combining gender, ethnicity, and housing, the highest poverty rates were experienced among Hispanic women who lived alone (39.5\%).

\section{Racial and Ethnic Composition}

The diversity of the older adult population in America is increasing, and will continue to increase for the foreseeable future. In 2014, non-Hispanic Whites accounted for $78 \%$ of the older adult population in the United States, but this is projected to drop dramatically to $55 \%$ in 2060 . The fastest-growing minority will be Hispanic elders of any race, almost tripling in percentage between 2010 and 2060 (from 8\% to 22\%), and overtaking Black elders as the dominant minority group. The growth in percentage of Hispanic elders over this half-century will be followed by older Asians $(4 \%-7 \%)$ and older Blacks (9\%-12\%).

Although health professionals will need to become more knowledgeable about the ethnic backgrounds of their older clients, there is great diversity within ethnic groups as well. Age, gender, region, religion, English-speaking skills, income, education, lifestyle, physical disability, marital status, place of birth, and length of residence in the United States are examples of important variables to consider within each ethnic group.

There is a continuum of acculturation that occurs among elders within each ethnic group. Acculturation is the degree to which people incorporate the cultural values, beliefs, language, and skills of the mainstream culture. To avoid stereotyping ethnic groups, there needs to be recognition of the many distinctive ethnic subgroups with varying degrees of acculturation (Haber, 2005).

\section{DEFINITIONS OF HEALTHY AGING}

Health professionals need to be careful about defining good health among older adults. This was the message delivered years ago by Faith Fitzgerald (1994) in an editorial in the New England Journal of Medicine cautioning against a narrow or rigid definition of health: "We must beware of developing a zealotry about health, in which we take ourselves too seriously and believe that we know enough to dictate . . the definition of health" (pp. 197-198). Is it people without chronic health conditions? That would be a highly exclusive club among older adults. Are physical and mental health equally important? Can we rely on the assessment of older adults about their own health? Can we 
QUESTION: What is your definition of healthy aging? trust the physician's or psychiatrist's judgment? Does the epidemiologist's data provide insight?

What follows is a sampling of definitions of good health.

\section{The Federal Government}

A broad and bland definition of health is provided by the federal government's Public Health Service through its Health Objectives for the Nation. It entails three components:

1. Disease prevention, which comprises strategies to maintain and to improve health through medical care, such as high blood pressure control and immunization.

2. Health protection, which includes strategies for modifying environmental and social structural health risks, such as toxic agent and radiation control, and accident prevention and injury control.

3. Health promotion, which includes strategies for reducing lifestyle risk factors, such as avoiding smoking and the misuse of alcohol and drugs, and adopting good nutritional habits and a proper and adequate exercise regimen.

\section{Extraordinary Accomplishments}

One not-so-bland definition of good health in late life is the lauding of extraordinary accomplishments by older adults who may serve as (unattainable?) role models. You can find these paragons of health everywhere in our multimedia culture. Here are some of my favorites.

\section{Arts}

Falstaff, Verdi's last opera, was composed when he was age 80. George Burns won an Oscar, his first, also at age 80. And Anna Mary Robertson, better known as Grandma Moses, had her first showing of her paintings at, you guessed it, age 80, after beginning this artistic pursuit just a couple of years earlier.

Enough with the youngsters. Herman Wouk, Pulitzer Prize-winning author of The Caine Mutiny, published his last novel, The Lawgiver, in 2012 at the age of 96 . He felt he needed a bit more seasoning before writing his first memoir, which was published in 2015 at age 100(!) entitled: Sailor and Fiddler: Reflections of a 100-Year-Old Author. Mr. Wouk died in 2019, a few days shy of his 104th birthday.

Mieczysław Horszowski, a classical pianist, recorded a new album at age 99. Johannes Heesters, a Dutch-born German singer-dancer-actor, was still appearing on stage at age 101. He announced at that age that he had no plans to take what he called "early retirement" because the stage was his life.

Jumping up to the age of 107, George Abbott collaborated on the revival of the musical Damn Yankees. George wasn't the only 107-year-old with an artistic bent. After Sadie and Bessie Delany wrote their bestseller: The Delany Sisters' First Hundred Years, Bessie died at age 104. Sadie then went on to author On My Own at 107: Reflections on Life Without Bessie. She died 2 years later at age 109.

\section{Politics}

In 2006, the average age of a U.S. senator was 62 years, the oldest it had ever been. (It declined slightly since then.) Not surprisingly, the term senate derives from the Latin word 
for "old." Golda Meir became prime minister of Israel at age 71. Former Senator John Glenn completed the rigorous physical preparation necessary to become the oldest space traveler in history at age 77. Former President Jimmy Carter won the Nobel Prize as a global peacemaker at age 78, and in 2018, at the age of 93, authored his 30th book, Faith.

Joe Newman, at age 101, ran for a seat in the House of Representatives from Florida's 16th congressional district in 2014. Apparently his long lifetime of experience went unappreciated. Joe got only 220 of the 274,829 votes cast, or . $1 \%$ of the vote. But you have to admire the gumption!

\section{Sports}

Kozo Haraguchi ran the 100 meters in 22.04 seconds, setting a record for the 95 to 99 age group. This 95-year-old Japanese man said he had to run cautiously because the outdoor track was slick with rain. Another runner, Johnny Kelley, won the Boston Marathon twice. Even more remarkable was that he had started this annual race 61 times during his lifetime, completing the entire 26.2 miles 58 times. Mr. Kelley died in 2004 at the age of 97. Another nonagenarian, though, continued to race in 2004. Fauja Singh moved from India to England and decided to take up running at the age of 82 . At the age of 92 , he set a world record for his age group by running the Toronto Marathon in 5 hours and 40 minutes.

Ken Mink was a basketball player at Roane State, a junior college about 35 miles west of Knoxville, Tennessee. The 6-foot, 190-pound player was listed as a senior on the basketball roster. No kidding! Ken Mink was 73 years of age in 2008, more than a half-century older than his teammates. In fact, this septuagenarian was the oldest person ever to play college basketball.

Since the Seattle Mariners are now the closest baseball team to me, I am a fan (though not as passionately as when I was a Brooklyn Dodger fan). So I need to add Evelyn Jones to this section of accomplishments. She celebrated her 108th birthday by throwing out the first pitch at a Mariners game, becoming the oldest person to perform this ceremonial pitch. She was an avid fan who watched every game and was given a uniform for this occasion with the number 108 on the back.

\section{Mountain Climbing}

Japanese mountaineer Tamae Watanabe set a world record in 2012 by becoming the oldest woman to scale Mount Everest, the highest mountain in the world. She did this at the age of 73. In 2013, 80-year-old Yuichiro Miura made it to the summit. Both are relative youngsters compared to Hulda Crooks, who climbed Mount Whitney, the highest mountain in the continental United States, at the age of 91.

Forty-six percent of Everest mountain climbers from 2000 to 2005 were age 40 or older, compared with just 19\% from 1953 to 1989.

\section{Work}

U.S. District Court Judge Wesley E. Brown became the oldest working judge in the nation's history. Near the end of his life, he had to transfer some of his work from his Wichita, Kansas, courtroom to his bedroom at home--because of his health-where he died a few weeks later at the age of 104. Judge Brown, however, was not the oldest worker in the United States. Ray Crist still worked as a research scientist at Messiah College in Pennsylvania at the age of 104. He had earned his doctorate in chemistry from Columbia University at the age of 26 and was still putting it to good use 78 years later. 


\section{Religion}

In 2009, 10 women ranging in age from 89 to 96 each memorized Hebrew in order to become a bat mitzvah, a Jewish girl who is marking the transition into religious adulthood. Unlike a bar mitzvah for a boy, a bat mitzvah was rare until the 1960s, and these women decided to make up for what they were denied as children. They met weekly for several months with a rabbi to study Hebrew to prepare for their rite of passage at the synagogue of the Menorah Park senior residence in Cleveland, Ohio. Although three used walkers and another carried a small oxygen tank to the podium, all successfully completed their deferred quest.

\section{Marriage}

After nearly three decades of dating, George Kirby, age 103, became the world's oldest groom in 2015. His bride, Doreen Luckie, was a mere 91 years old. George revealed that he didn't get down on one knee because he wouldn't have been able to get up.

\section{Birthing}

A California woman named Arceli Keh lied about her age (she said she was 51 but was actually 61) in order to become eligible for a fertility program in which she was implanted with an embryo from an anonymous donor. In 1996, at age 63, she became the oldest woman on record to have a baby. Her record was surpassed in 2006 when Maria del Carmen Bousada, a 66-year-old Spanish woman, who had become pregnant after receiving in vitro fertilization treatment, gave birth to twins by cesarean section in a hospital in Barcelona. The wisdom of this accomplishment was called into question in 2009, however, when she died from cancer at age 69, leaving behind boys not yet 3 years old.

Nonetheless, fertility science marches on. In 2013, in the United States, 677 women age 50 or older gave birth, most via in vitro fertilization with donor eggs. The risks are substantial, though, with these older mothers much more likely to become diabetic or hypertensive and babies facing complications from low birth weights.

\section{Bank Robbing}

Red Rountree, at the age of 91, became the oldest known bank robber in U.S. history in 2004. Sentenced to a 12-year term in Texas-he died within the first year of his sentence-Red said he robbed banks for fun: "I feel good, awfully good for days after robbing a bank." After two successful heists, the third time apparently was not the charm. The teller at the third bank, responding to his demand for money, asked, "Are you kidding?"

Although I marvel at these examples of unusual achievement by aging adults, I do not personally use them as inspiration for older, or even younger, persons. These models are astonishing, but they do little to enhance the confidence of aging adults who do not believe they can-and perhaps do not want to-come close to achieving similar milestones.

As Friedan (1993) noted in her book The Fountain of Age, as an older adult one may "attempt to hold on to, or judge oneself by, youthful parameters of love, work and power. For this is what blinds us to the new strengths and possibilities emerging in ourselves."

Nonetheless, I had an uproariously good time compiling these accomplishments. 


\section{Prevention}

Prevention is often categorized as primary, secondary, or tertiary (Figure 1.9). Primary prevention focuses on an asymptomatic person in whom potential risk factors have been identified and targeted. Primary preventive measures, such as regular exercise, good nutrition, smoking cessation, or immunizations, are recommended to decrease the probability of the onset of specific diseases or dysfunction. Primary prevention is different from health promotion in that it is less broad in scope and tends to be the term used by clinicians in a medical setting.

Secondary prevention is practiced with an asymptomatic person in whom actual (rather than potential) risk factors have been identified even though the underlying disease is not yet clinically apparent. A medical screening, as an example of secondary prevention, is cost-effective only when there is hope of lessening the severity or shortening the duration of a pathological process. Blood pressure screenings, cholesterol screenings, and bone densitometry are the most widely implemented forms of secondary prevention.

Tertiary prevention, which takes place after the person with a disease or disability becomes symptomatic, focuses on the rehabilitation or maintenance of function. Health professionals attempt to restore or maintain the maximum level of functioning possible, within the constraints of a medical problem, to prevent further disability and dependency on others.

Tertiary prevention corresponds to phase 2 (rehabilitation of outpatients) and phase 3 (long-term maintenance) of the rehabilitation of a cardiac patient (phase 1 is the care of a hospitalized cardiac patient). Randomized clinical trials with patients who had myocardial infarctions revealed that programs of tertiary prevention reduced the likelihood of cardiovascular death by $25 \%$.

A focus on prevention may be more appealing to some older adults than an emphasis on health promotion. Older adults are likely to be coping with chronic conditions, and the prevention, delay, or reduction in disability and dependency is a much more salient issue for them than it is for most younger adults.

Moreover, among medical professionals, the relevancy of the term prevention is enhanced because the costs of many prevention activities, such as mammograms, are reimbursable through Medicare. Prevention has gotten its foot in the door, so to speak, in the system of healthcare reimbursement, whereas the activities of health promotion have lagged considerably behind.

One advantage of the use of the term health promotion, however, is that it encompasses mental, emotional, and spiritual health concerns. In contrast to clients and health professionals fixated on risk factors and the prevention of disease or disability, health promotion or wellness can be viewed as an affirming, even joyful, process. As health professionals who promote health, for instance, we can encourage playing with grandchildren or the joy of bird watching to an older client and not concern ourselves with its ability to prevent disease or illness.

Health promotion is also a more proactive approach than primary prevention, which tends to imply a reaction to the prospect of disease. Directing a client's anger or

FIGURE 1.9 Three levels of prevention.

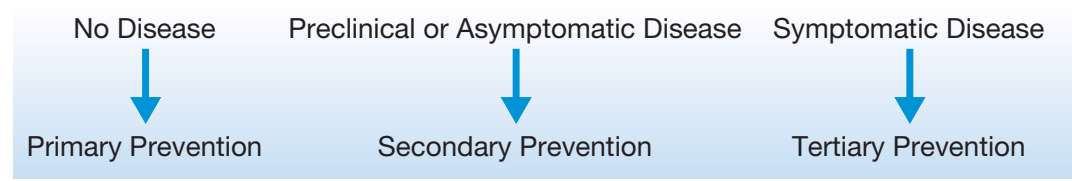


frustration into political advocacy work, for example, is a proactive, health-promoting enterprise that benefits both the client and society.

\section{Wellness}

Although the term wellness has had many supporters in the health professions over the years (Jonas, 2000), particularly among persons who conduct health programs at large U.S. corporations (J. Jacob, 2002), it tends to be embraced less than the terms health promotion and disease prevention. Nonetheless, wellness conveys an important message- that good health is more than physical well-being. In fact, seven dimensions are usually touted among wellness advocates, as shown in Table 1.5.

Wellness sends a welcome and important reminder about the breadth of health promotion that is not conveyed by most other terms. The only limitation to the term wellness is that it tends to be identified with "alternative" activities-acupuncture, homeopathy, spiritual healing, aromatherapy-to the exclusion of more mainstream activities such as exercise and nutrition. Thus, it suggests fringe pursuits or even flakiness to some.

\section{Antiold and Antiaging}

Who is healthier, an old person or an older adult? Is this a preposterous question? Maybe not. Do the terms old person and older adult reflect our prejudices-the frail old person versus the more neutral older adult? One of the leaders in the field of gerontological language, Erdman Palmore, thought so. Palmore suggested that most of the synonyms for old are unhealthy in some way-words like debilitated, infirm, and frail. Older adult, on the other hand, is a more neutral and relative term-a 40-year-old can be an older adult to a teenager.

Palmore suggested that perhaps the term elder connotes the healthiest definition for older persons in society (Palmore, 2000). In Christian churches, for example, elder is a person who is valued for his or her wisdom and who holds a position of responsibility and authority. Among the general public, however, the term appears to be viewed no more favorably than other synonyms for old.

Surveys of AARP members have revealed that no synonyms for old are acceptable, not seniors, not elders, not mature adults. As a result, AARP in its magazine entitles its movie review section, "Movies for Grownups."

\section{TABLE 1.5 SEVEN DIMENSIONS OF WELLNESS}

Physical-Exercise, eat a well-balanced diet, get enough sleep, protect yourself.

Emotional-Express a wide range of feelings, acknowledge stress, channel positive energy.

Intellectual-Embrace lifelong learning, discover new skills and interests.

Vocational-Do something you love, balance work with leisure time.

Social-Laugh often, spend time with friends/family, join a club, respect cultural differences.

Environmental-Recycle daily, use energy-efficient products, walk or bike, grow a garden.

Spiritual-Seek meaning and purpose, take time to reflect, connect with the universe. 
And yet I am reminded of an anecdote about Maggie Kuhn, the founder of the advocacy organization the Gray Panthers. She reported on an exchange that she had with President Gerald Ford at a hearing on a pension bill in Washington, DC. Once she had gotten President Ford's attention, he asked, "And what do you have to say, young lady?" Maggie replied, "First of all, I'm not a young lady. I'm an old woman." She was making the statement that she was proud of being old, and that she had earned that label.

A related concern is the antiaging movement and its chief proponent, the American Academy of Anti-Aging Medicine. This professional society is "pursuing the fountain of youth with their lucrative nostrums and illusory interventions, [while] we geriatricians remain solidly in the trenches caring for our patients, the most aged, complex, frail, and vulnerable - far removed from the fantasies of eternal life, much less the fountain of youth" (Hazzard, 2005, p. 1435).

Not-so-fun fact: There are more physicians in the American Academy of Anti-Aging Medicine (a field not recognized by any legitimate medical certifying body) than there are board-certified geriatricians (who are, in fact, declining in number).

Most proponents of the antiaging movement are focused not on the most aged, but on the middle-aged and the young old, those most concerned with combating the signs of aging. One key weapon in their arsenal is the cosmeceutical, a combination of the terms cosmetic and pharmaceutical that refers to a topical skin treatment formulated to eliminate the wrinkles and other signs of aging. If the cosmeceutical intervention proves insufficient, there are Botox injections, microdermabrasion, chemical peels, collagen injections, and plastic surgeries. Antiagers deliver a clear message that aging is a disease that needs to be cured-at least cosmetically and temporarily.

Another segment of the antiaging movement believes in the power of human growth hormone (HGH). Ironically, while the target audience is the middle-aged and the younger old crowd, Don Ramos of Colorado Springs, age 80, was suspended for 2 years by the U.S. Anti-Doping Agency for testing positive for an anabolic steroid, a growth hormone, at the Pan American Master's Weight Lifting Championships.

A review of 31 randomized, controlled studies, however, concluded that the risks outweigh any potential antiaging benefits of HGH when taken by healthy older adults (Liu et al., 2007). Side effects may include diabetes, hypertension, hardening of the arteries, and abnormal growth of bones or internal organs.

Nonetheless, government officials estimate that 25,000 to 30,000 Americans take injections of $\mathrm{HGH}$ for antiaging purposes, paying up to $\$ 1,000$ a month. Although it is illegal to prescribe HGH for healthy people in the United States, speakers at the annual conference of the American Academy of Anti-Aging Medicine have told physicians in the audience how they can diagnose a mild hormone deficiency so that they can legally prescribe HGH (Wilson, 2007).

I think, however, that we need a proaging movement, one that emphasizes the healthy aspects of aging and the benefits that accrue with age. No longer needing to impress employers, in-laws, or peers, older adults are free to be themselves. The old have the opportunity to be not only freer, but also wiser, more conscious of the present, and more willing to be advocates for a healthy future. Maggie Kuhn certainly practiced a proaging lifestyle.

I am not the first to use the term proaging. Over the last few years advertisements for Dove beauty products have consistently asked the question "Are you antiage or proage?" Unfortunately, Dove's proage movement consisted entirely of selling moisturizers and other skin products. This is not what I have in mind when I talk about promoting a healthy attitude toward aging. (Not that I have anything against reasonably priced moisturizers.) 
Finally, the Me Too movement rose to prominence worldwide at the end of 2017. It took a strong stand against sexual harassment. From a gerontological perspective, though, there is also a lot of work remaining to be done. In Italy, according to Roman prosecutors, older women are exempt from sexual harassment. They dismissed a groping case brought by 53-year-old Elisabetta Cortani. Verdict? She was too old to be distressed by sexual advances!

\section{Compression of Morbidity}

By definition, chronic diseases are not curable. The onset of chronic disease, however, may be postponed through the modification of risk factors. As the onset is delayed to later ages and approaches the limit of the human life span, the result is a compression of morbidity. The goal is to live in robust health to a point as close as one can come to the end of the life span, so that one can die after only a brief period of illness. In short, spend a longer time living and a shorter time dying.

For most people, though, the prospect of living long past one's 65th birthday is a mixed blessing. With Americans living longer today than ever before, we have come to dread a prolonged period of disability and dependency in late life.

One definition of healthy aging, then, is to be able to live life fully until death. Pessimists argue that the period of morbidity preceding death will lengthen in the future as a result of (a) limited biomedical research funds available to improve the physical and mental capacity of the very old; (b) the fact that some major diseases, such as Alzheimer's, do not have recognized lifestyle risk factors that we can modify; and (c) medical advances, such as dialysis and bypass surgery, that will increase the life expectancy of those with disease rather than prevent the occurrence of disease.

Optimists, however, claim that there will be a compression of morbidity (see Figure 1.10) in the future due to (a) the likelihood of advances in biomedical research that will prevent or delay the occurrence of disease and (b) the continued potential for reducing risk factors such as smoking, high blood pressure, poor nutritional habits, and sedentary lifestyles, which will result in better health.

Even as the general population further delays the onset of chronic disease due to these risk factors, the life span - the maximum number of years for a member of the species-is likely fixed. Thus, argue the compressionists, we will not only delay morbidity, but we will also shorten it.

The research into compression of disability, though, has not reached a consensus. One study, for instance, did not support evidence of a compression of morbidity. Over the

FIGURE 1.10 Compression of morbidity.

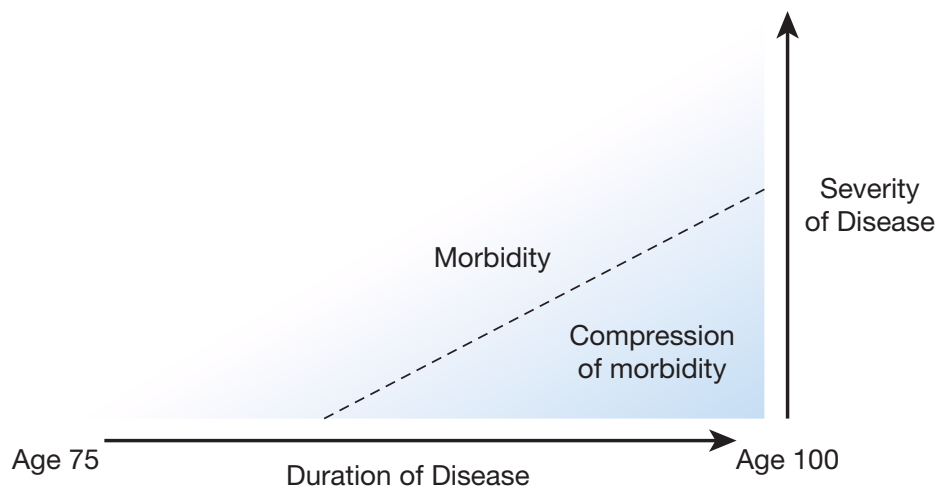


prior decade, length of life with disease and deteriorating function of mobility increased (Crimmins \& Beltran-Sanchez, 2010). While longevity increased, living with disease increased as well. A later study by one of the same researchers concluded the reverse. Over a 40-year period, 1970-2010, disability-free life expectancy in the United States increased for those age 65+ and for those age 85+ (Crimmins, Zhang, \& Saito, 2016).

What seems to be the most credible research outcome is that given the right combination of healthy lifestyle behaviors, compression of morbidity can be accomplished. One such study supports this conclusion, examining smoking and alcohol habits, physical activity, diet, body mass index (BMI), and social support (M. Jacob et al., 2016). In a given population, the healthier the lifestyles overall, the more likely compression of morbidity will take place. The challenge, of course, is how to encourage healthy lifestyles in a society in which some risk factors are declining (smoking, for instance) while others are increasing (obesity).

Will we be able to foster the compression of morbidity? It is not certain at this time. Moreover, will there be improved medical advances and medical access that compresses morbidity? Will there be societal improvements such as increased education levels and income levels that compress morbidity?

My compression of morbidity vision is to live into my 90s, dribble down a basketball court, leap into the air, dunk a basketball, and after I observe the ball falling through the net but before it hits the ground, I die of a heart attack. Now that's compression of morbidity! (I've still got some work to do on the dunking part.)

\section{HEALTH PERSPECTIVES AND AGING}

\section{Health Expectancy Versus Life Expectancy}

Almost everyone is familiar with the term life expectancy, the average length of time human beings are expected to live. A less familiar term is health expectancy, the amount of time human beings are expected to live in good health and free from functional limitations. There is, on average, a 5-year gap between life expectancy and health expectancy after the age of 65, according to the CDC's Behavioral Risk Factor Surveillance System.

Place yourself in the shoes of the person who has just reached age 65. Are you primarily interested in remaining alive as long as possible, or are you most interested in how many of your remaining years will find you healthy and functionally independent? Most older adults I have conversed with over the decades indicate the latter is more important to them.

Your health expectancy depends to a great extent on your level of physical activity, nutritional intake, social support network, access to good medical care, health education, and utilization of health services. While health expectancy is more important to older adults than life expectancy, unfortunately we have not made adequate progress on this front. As noted in the beginning of this chapter, the goal of Healthy People 2000 was to increase the number of years of healthy life remaining after age 65 from 11.8 to 14 . It increased only to 12.2 years, an advance of 4 months over the decade.

\section{Physical Versus Emotional Aspects of Aging}

There is a strong reciprocal relationship between the physical and emotional aspects of health. When our physical health is threatened, so typically is our emotional health. The converse is equally true. 
As we age, however, it may be the case that good health becomes less dependent on our physical status than on our emotional status. Studies report shifting perspectives of health over time, with older participants expecting physical health problems because of their age and discounting them somewhat, when they do appear, because of this expectation.

A study of 85-year-olds living in the Netherlands reported that physical function was not the most important component of successful aging. These older adults were able to adapt successfully to physical limitations. The researchers reported social contacts as the most important factor in well-being, and the quality of the contacts was more important than their number (von Faber et al., 2001). Open-ended interviews reveal more than 100 characteristics of health that are important to older adults besides physical health, including the ability to enjoy life and good personal relationships. Many older adults who are frail and sometimes disabled do not evaluate their health or life negatively.

Most health professionals subscribe to the notion that health is more than the absence of illness. Were this not the case, they would have to label the vast majority of older adults, $90 \%$ of whom are coping with a chronic condition, unhealthy. The chronic diseases that older persons contend with do not necessarily relate to their ability to perform daily activities. Disease, in fact, may not be evident even to the person who has it.

The presence or absence of disease, therefore, may not be a source of great concern to older adults. The ability to perform ADLs, however, is of great concern to older adults who desire as much independence as possible. The definition of health, especially among older adults, should not be linked with disease or its absence, as the medical model suggests, but with independence, the ability to accomplish one's goals, and the presence of satisfying relationships.

A health perspective that emphasizes the psychological status of older adults does not view health as a physical continuum ranging from disability and illness at one end to a high level of robustness at the other. Critics of this type of health continuum argue that even a person who is functionally impaired or disabled, and thus residing at one end of the physical continuum, can focus considerable attention on a high level of wellness and psychological growth.

Finally, health professionals walk a fine line with older patients. On the one hand, they have been accused of ignoring some of the medical needs of older adults by discounting the viability of certain medical interventions because of advanced patient age. In fact, most patients in their 80 s can benefit as much from surgical interventions as can younger patients (Varghese \& Norman, 2004).

On the other hand, health professionals can unduly focus on the (reimbursable) medical needs of very old clients and neglect the personal values that inform the quality of life of the older adult. Many older adults, if informed, would avoid the prospect of high-risk surgeries that are unlikely to extend quality of life or perhaps even life expectancy. An example is a study of almost 6,000 frail nursing home residents most of whom were in their 80 s and cognitively impaired. The questionable decision to do breast cancer screenings on these residents led to surgeries that did not extend their life and most certainly did not improve their functioning or quality of life (Tang et al., 2018).

\section{Intergenerational Conflict Over Healthcare?}

Creating a name for a generation and then generalizing about it is fraught with complexity, and some analysts shy away from it-but many do not. I personally think it is a type of intellectual fun that analysts and the general public find hard to resist. If you are 
among them, there is an interesting argument to be made that there will be generational conflict over healthcare expenditures in the future. But first, there are three generations to define.

The baby boomers refer to those born between 1946 and 1964. Many argue that people born up to two decades apart are too diverse for one label (Pruchno, 2012). In fact, some differentiate between leading-edge boomers (1946-1955) and trailing-edge boomers (1956-1964).

Leading-edge boomers are more likely Caucasian, married, college graduates, and more than twice as likely to have served in the military than trailing-edge boomers. The latter difference is due to the fact that the draft ended after all the leading-edge boomers had turned age 18. Is it wise to lump both groups together? Then throw in the technology revolution to complicate matters. Smartphone ownership by leading-edge boomers is only two-thirds that of trailing-edge boomers.

The boomers are differentiated from generation X, born between 1965 and 1981, and generation $Y$, also referred to as the millennials, born between 1982 and 2000. Some argue that these two generations not only differ from each other but are too diverse within each generation for one label per group. Within each of these generations, are there shared values about hard work, trust, respect for authority, teamwork, competition, privacy, independence, optimism, and so forth, as some analysts claim without much supporting data?

Complicating generalizations about the millennials is that they make up one-quarter of the U.S. population. In 2015, this huge cohort surpassed the number of boomers.

In one area, though, I can see the utility of differentiating generations and the potential for intergenerational conflict, and that is over healthcare. Let's face it. The boomers use a lot more of it, thanks to aging bodies and Medicare, than do generation $X$ and the millennials. There is insufficient national wealth for all Americans to get all the medical care they desire. One can see the boomers wanting to preserve the benefits of Medicare that they currently (or soon will) get, which is costly to all taxpayers, even the ones who will not be able to take advantage of it for several decades-or may eventually take advantage of it with significantly reduced benefits, according to some skeptical millennials.

The younger generations may resent the expensive cost of Medicare and other resources that older adults disproportionately use, versus government support for education, child support, and the other needs that disproportionately affect younger adults. Millennials, though, may have complex feelings about their boomer parents. They may resent the growing debt awaiting them for decades and perhaps for the rest of their lives. But the percentage of young adults between the ages of 18 and 34 who are living with their parents had increased to 32\% in 2016 (and for the first time this is a higher percentage than those living with a partner!). It is hard for millennials to resent Medicare and other resources that older adults disproportionately use while at the same time taking advantage of the voluntary generosity of the older generation.

Intergenerational conflict over jobs may be less likely than conflict over healthcare. According to Munnell and Wu (2012), there is no evidence that increasing the employment of older persons reduces the job opportunities or wage rates of younger persons.

\section{LEGISLATION}

Medicare, Medicaid, and Social Security have had a tremendous impact on health. It is important, therefore, to review these legislative acts, as many people do not even understand the difference between Medicare and Medicaid, so we begin there. 


\section{Medicare}

Medicare was enacted in 1965 to help persons age 65 or older pay for medical care. In 2016, Medicare covered 48 million older adults and 9 million younger persons with disabilities. It is a major player in the U.S. healthcare system, costing $\$ 702$ billion in 2017, an increase in costs of $40 \%$ from a decade earlier and currently $15 \%$ of the entire federal budget.

Ironically, despite the generous reimbursements that beneficiaries received through the Medicare program in $2014(\$ 11,000)$, older Americans spent more money out of pocket (about $\$ 5,000$ per beneficiary), after controlling for inflation, than they did prior to the inauguration of Medicare. These costs include Medicare premiums, deductibles, and coinsurance; eyeglasses and hearing aids along with vision and hearing tests; dental care; over-the-counter drugs; and long-term care. Out-of-pocket medical care costs consume more than one-third of the average Social Security check.

Medicare Part $A$ is referred to as hospital insurance, and most people do not have to pay a monthly premium for this insurance because they are eligible through the taxes they paid while working. Part A includes hospital care (\$1,316 deductible in 2019), inpatient psychiatric care (190-day lifetime maximum), skilled nursing facility care (100 days), rehabilitation or home care following a hospitalization, and hospice care for the terminally ill. There are restrictions on what kinds of conditions are covered and the length of coverage. Copayments apply as well.

Medicare Part B is referred to as medical insurance and covers physician services, outpatient hospital care, and other medical services such as physical and occupational therapy and some home healthcare. Part B requires a premium for most people $(\$ 85,000$ a year or less) of $\$ 134$ per month in 2019 and generally pays $80 \%$ of physician and outpatient services after an annual $\$ 183$ deductible. Part B includes most medical screenings and clinical laboratory tests but does not cover dental services, hearing aids, eyeglasses, and most long-term care services. Chronic conditions are, for the most part, not covered by Medicare Part B, and prevention coverage is limited primarily to medical screenings and immunizations.

Beginning in 2007, Medicare shifted, for the first time, to means-based testing for Part B premiums. Only persons earning less than $\$ 85,000$ a year $(\$ 170,000$ for married couples) pay the base premium; those who exceed this income level have their premiums increased, based on how much additional income they earned. Use of this type of income indexing will continue to increase in the coming years, and some project that beneficiaries with high incomes may pay at least three times the basic premium amount.

Medicare Part $C$ refers to private health insurance plans that provide Medicare benefits, that is, Medicare Advantage plans. At the time of this writing, there was a subsidy at taxpayers' expense granted to private insurers under Part $C$ that was unavailable for those opting for the traditional Medicare option. If this discrepancy continues, the number of private health insurance beneficiaries will continue to increase. Another factor that is likely to increase enrollment in Medicare Advantage plans is coverage for nonskilled in-home services for selected beneficiaries, beginning in 2019.

Medicare Part D refers to the Medicare prescription drug plan, which went into effect on January 1, 2006. This part is also administered by private health insurance companies. Thanks to powerful lobbyists during the Bush Administration, Medicare Part D does not allow the government to negotiate with drug companies to lower prescription drug costs for beneficiaries, despite the fact that Medicaid and Veterans Affairs are able to do this to control costs.

About one-fourth of federal health expenditures for older adults is for Medicare, and these expenditures have been rising (and will continue to rise) rapidly. It is not 
surprising, therefore, that even though the single largest component of out-of-pocket costs for older adults is for much needed long-term care, it will not be enacted by Medicare anytime soon. Except for the rare initiative, the federal government has resisted overtures to include substantial long-term care coverage under Medicare. One attempt, the CLASS Act (Community Living Assistance Services and Supports Act-one of many ridiculous acronyms I will share with you throughout this book), was proposed under the Affordable Care Act. However, this revolutionary proposal was quickly dropped because it was designed as a voluntary program-politically desirable but financially unfeasible.

An interesting line of research has shown that Medicare spending across the country varies greatly, but health outcomes tend to be the same regardless of how much money is spent in a particular region. Some argue, therefore, that Medicare costs could be reduced significantly if the entire nation could bring its costs down to match the lower spending regions.

Landrum, Meara, Chandra, Guadagnoli, and Keating (2008) agree with this premise, with one caveat. Although increased area-level spending does not correlate with improved patient outcomes overall, in certain cases increased spending is beneficial. The problem is that high-spending areas also spend too much money on healthcare problems where little or no benefit results. The authors concluded that Medicare could save money not by capping costs, but by applying comparative effectiveness studies, that is, determining which treatments work best for which patients, and whether the benefits are commensurate with the costs.

The Centers for Medicare and Medicaid Services oversees all financial and regulatory aspects of the Medicare and Medicaid systems. For additional information, call 800-MEDICARE (800-633-4227) or go to the Medicare website (www.medicare.gov).

\section{Medicaid}

Medicaid is different from Medicare in that it is:

1. Not focused primarily on older adults

2. A state-run, not a federally managed, program

3. Funded jointly by the states and the federal government, not by the federal government alone

4. The largest source of funding for medical and health-related services for people with limited income-what used to be referred to as a welfare program-as opposed to Medicare, which is partially financed by users through payroll taxes, and considered to be an entitlement program

Because it is state run, Medicaid policies for eligibility, services, and payment vary considerably by state (and because of the Supreme Court decision on June 28, 2012, which allowed states to opt out of the Medicaid component of the Affordable Care Act, this variation has become even more extreme). One aspect of Medicaid that has not varied much across states is that costs have increased steadily throughout the years and now constitute, on average, a quarter of each state's budget. Medicaid spending totaled \$566 billion in 2016.

On a gerontological note, one-third of Medicaid's budget goes to fund long-term care for the frail elderly and the disabled, most of it to nursing homes. It pays for about $60 \%$ of nursing home care, and an increasing amount of home- and community-based long-term care. Medicaid is based on the premise that people pay out of pocket until they become impoverished and eligible for coverage. Moreover, an older person cannot 
shelter money by giving it away to a relative within a 5-year period of qualifying for Medicaid-subsidized long-term care.

Medicaid, unlike Medicare, has no influential constituency advocating on its behalf. It is recognized by the general public as a program for low-income people and many do not feel generous with their tax dollars to support it. With federal deficits looming as far as the eye can see, and with Medicaid the largest cost item in most states' budgets, the pressure to reduce Medicaid expenditures is and will continue to be enormous. This is likely to have a strong and negative impact on the quality of long-term care for low-income older adults and disabled persons.

\section{Social Security}

Few would argue that inadequate income is irrelevant to health. It is important, therefore, in a book focused on health and aging to examine Social Security. Social Security is a federal program designed to protect people and their families from loss of earnings due to retirement, disability, or death (when signed into law in 1935, it covered only retired workers). It was believed by historians that President Franklin Roosevelt was interested not only in the economic security of older adults, but in reducing the politically sensitive high unemployment rate at the time.

Social Security is a progressive benefit, replacing a higher proportion of preretirement earnings of low lifetime earners than higher lifetime earners. Additional protection was provided in 1975 when the Social Security benefit was to be adjusted annually to reflect increases in prices (the Cost of Living Adjustment, or COLA).

It is an entitlement in that to receive retirement benefits, a person must contribute through payroll tax contributions for 10 or more years. Workers and employers are both responsible for paying half of the payroll tax $-6.2 \%$ each, with the self-employed paying the full $12.4 \%$, up to a taxable maximum of $\$ 132,900$ (in 2019) of earnings.

In 2017, 61 million Americans-retired workers; spouses, children, and survivors; and the disabled-received Social Security benefits, about $90 \%$ of those age 65 and older. The average monthly benefit for retired workers in 2018 was $\$ 1,404$, and for disabled workers it was $\$ 1,197$.

Without access to Social Security, $58 \%$ of women and $48 \%$ of men above the age of 75 would be living below the poverty line. Even though Social Security was initially designed to be a partial replacement of lost income, it has become almost the entire income of many retired persons. In 2018, more than one-third of beneficiaries relied on their Social Security checks for $90 \%$ or more of their total income, including half of older women!

Another problem is a societal one: meeting the financial obligation. In 1935, only $6 \%$ of the population was age 65 or over; in 2016, that percentage had increased to $15 \%$. Contrary to this increase in older adults, there were approximately 4 workers per beneficiary in the 1960s, 2.9 workers in 2012, and a projected 2.1 workers in 2036. The widening gap between those paying into Social Security and those receiving Social Security means that full benefits will be reduced in 2034 to about $81 \%$ of scheduled payments, but only if changes are not made.

\section{HEALTHCARE, MEDICAL CARE, QUALITY CARE}

In a democratic society there is stiff competition for societal resources that are taxpayer subsidized. However, healthcare (most of our healthcare expenses are actually for medical care) has consistently maintained its status in this country as a very high priority for these limited resources. 
The growth in national expenditures for healthcare has been nothing short of phenomenal. Spending for national healthcare grew from $6 \%$ of the gross domestic product (GDP) in 1970

QUESTION: Why do we call medical care "healthcare"? to an astonishing 18\% in 2017 (Figure 1.11). Healthcare spending reached $\$ 3.4$ trillion in 2017 , or $\$ 10,740$ per person!

While the United States is spending about $18 \%$ of its GDP on healthcare, other developed countries spend between $9 \%$ and $11 \%$-with most having single-payer systems. In this latter category falls Denmark, which spends $10 \%$ of overall expenditures on healthcare, yet this country ranks the highest among developed countries for patient satisfaction with their healthcare system-90\% satisfied or very satisfied (Pederson, Andersen, \& Soundergaard, 2012).

Much of this discrepancy in U.S. healthcare costs compared with other countries began in 1980 with the rise of private healthcare insurers in the United States (and their profit-making motivation) and the greater use of sophisticated, and expensive, medical technology in this country. In the past three decades, health expenditures doubled in other countries, but more than tripled here.

Although we spend more on healthcare than any other country, this does not necessarily mean we have the best healthcare. "Best" can be defined in a number of ways, such as the already mentioned patient satisfaction, but also as access to medical care by the greatest number of citizens, or as a system that prioritizes disease prevention and health promotion, or as in contemporary America, a system that prioritizes costly specialized medical procedures.

The World Health Organization (WHO) and others have measured quality of healthcare and, by almost any measure, we do not do well. WHO ranked the United States 37th in the quality of healthcare. We are 50th in life expectancy. We just do not get enough "bang for our buck." Regarding number of healthy years we have to live-a

FIGURE 1.11 Total national health expenditures as a percentage of gross domestic product, 1970-2017.

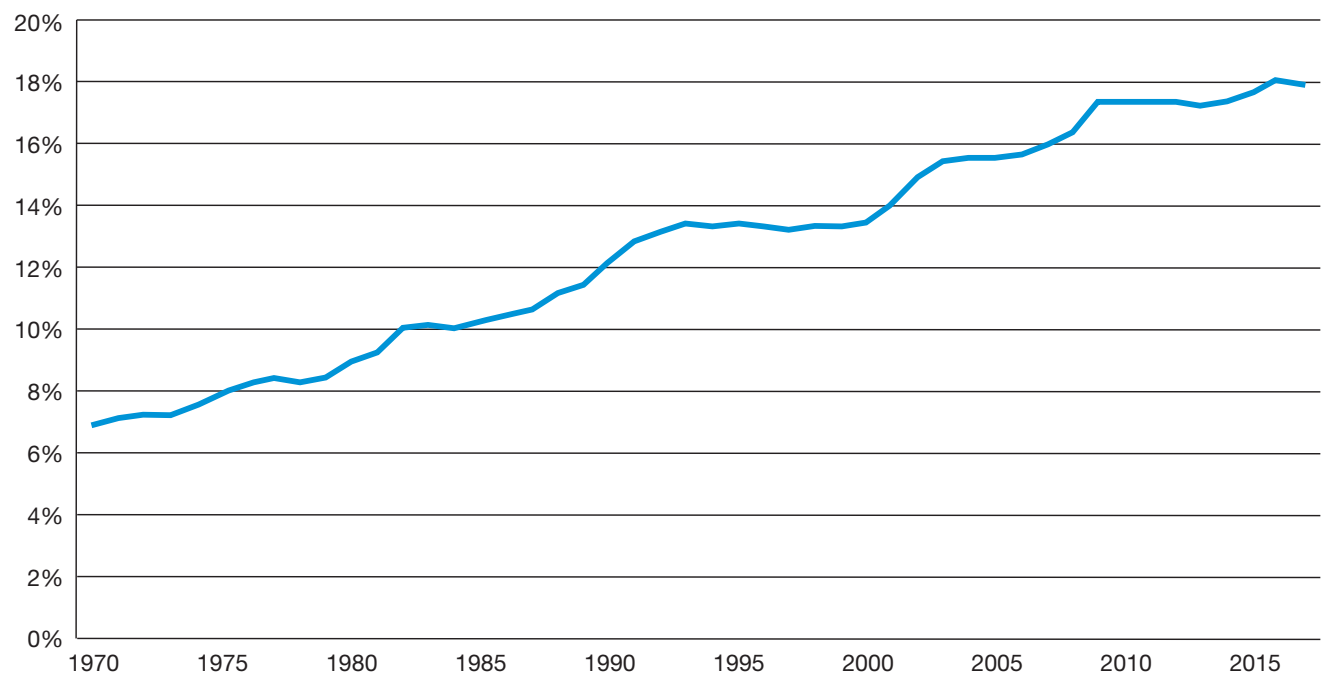

Source: Kamal, R., \& Cox, C. (2018, December 10). How has United States spending on healthcare changed over time? Retrieved from https://www.healthsystemtracker.org/chart-collection/u-s-spending-healthcare-changed-time 
more important measure of quality of life, in my opinion, than mere life expectancywe spend more than double in healthcare expenditures per capita than Japan, but have almost 5 fewer healthy years to live than they do.

Another international study of healthcare quality was conducted in 2006, and the United States ranked last compared with Australia, Canada, Germany, New Zealand, and the United Kingdom. The per capita health expenditures of these five countries ranged from $33 \%$ to $53 \%$ of the United States, yet among 51 indicators-including such health promotion measures as use of mammograms, flu shots, medication reviews, and diet and exercise advice- - the United States ranked last or tied for last on 27 (Monaghan, 2006).

One international study compared the United States, Australia, Canada, France, Germany, the Netherlands, New Zealand, and Britain, and suggested that the supremacy of American healthcare may be limited to a handful of preeminent medical centers (Schoen, Osborn, How, Doty, \& Peugh, 2009). Although the United States does well in such important aspects of healthcare as providing prompt access to some of the best specialists in the world, 43\% of insured (!) Americans skipped care at some point during the year because they could not afford the high out-of-pocket costs (Schoen et al., 2009).

\section{Healthcare Versus Medical Care}

It is estimated that $60 \%$ of early deaths in the United States are due to behavioral, social, and environmental circumstances, versus $10 \%$ that result from shortfalls in medical care (with genetic predisposition responsible for the remainder; McGinnis, Williams-Russo, \& Knickman, 2002). Paradoxically, however, the behavioral, social, and environmental components of healthcare have not constituted a high priority for the healthcare dollar. In fact, only about 3\% of the nation's healthcare expenditures are targeted toward health-promoting and disease-preventing activities.

Most of that 3\% goes either to the physician's office or to other clinical settings for preventive measures, such as medical screenings and vaccinations (about a third), or toward health protection in the physical environment, such as toxic agent and radiation control (also about a third). And only a portion of the remainder is spent on changing unhealthy behaviors.

Although there has been undeniable financial stinginess at the federal level in addressing unhealthy lifestyles among the American people, public attention has at least been engaged by this problem behavior ever since the publication of the landmark document Healthy People: The Surgeon General's Report on Health Promotion and Disease Prevention (USDHHS, 1979). This report provided considerable credence to the idea that major gains in health and independence in the future can come from personal lifestyle changes.

Dr. John Rowe, director of the MacArthur Foundation's Consortium on Successful Aging, supported this report's message by concluding that our vigor and health in old age are mostly a matter of managing how we live. A classic article in the Journal of the American Medical Association (McGinnis \& Foege, 1993) suggested that we no longer should view death as being due to heart disease, cancer, stroke,

QUESTION: In your opinion, what are two of the most important changes we need to make to convert our medical care system into a healthcare system? How can we make these changes? and chronic obstructive pulmonary disease; rather, we should see it as the result of tobacco use, inactivity, poor diet, alcohol abuse, microbial and toxic agents, risky sexual behavior, motor vehicle injuries, and illicit or inappropriate use of drugs. 
We undoubtedly will continue to devote most of our money to medical care, but we need to focus more of our attention and resources on healthcare.

\section{SUMMARY}

The field of health promotion has come a long way since it was initially defined as exercise, nutrition, and smoking cessation. Moreover, older adults were typically excluded from early writings on health promotion and disease prevention. They were old after all, perhaps resistant to change and without much of a future.

Health promotion and aging now cover dozens of topics. Here is just a sampling: the improving health habits of older adults regarding exercise, diet, nonsmoking, and health information seeking; the impact of increasing education and empowerment with age on health status; the reduction in poverty and its impact on the health of older adults due to the success of Medicare and Social Security; the burgeoning and exciting healthy aging program initiatives at the national, state, and community levels; the influence of older adults on politics and public policy on health and income due to their greater involvement in leadership positions and the high percentage of older voters; the participation of older adults in environmental advocacy and the health of our planet; the encouraging research into the association of age with wisdom, emotional resilience, spirituality, volunteerism, and social connectedness; the extraordinary accomplishments in many fields of endeavor by older adults; the confrontation with and reduction in ageism; the increase in not only life expectancy, but health expectancy; the promise of compression of morbidity in old age; and so much more. Anyone who is interested in life is interested in health promotion and aging.

Which brings us to aging. While many health science students have preferred to focus on children and young adults because of the potential to influence persons over a lifetime, others increasingly believe the real action is with older adults. Why? First reason: There are so many of us (yes, the author is old). Older adults will outnumber children under the age of 18 in 2034-for the first time in American history. Keeping older adults as independent as possible saves countless dollars and resources (disproportionately spent on older patients) that can improve the health and prosperity of society in general. Second reason: There is an immediacy to disease prevention and health promotion in late life that leads to an openness to learn and change. If not now, when? Older adults realize that there is no longer a seemingly endless amount of time left. We are enthusiastic learners and doers-how exciting to work with us!

\section{REFERENCES}

Administration for Community Living \& Administration on Aging. (2018). 2017 profile of older Americans. Washington, DC: U.S. Department of Health and Human Services. Retrieved from https://acl.gov/sites/default/files / Aging\%20and\%20Disability\%20in\%20America/2017Old erAmericansProfile.pdf

Binstock, R. (2009). Older voters and the 2008 election. Gerontologist, 49, 697-701. doi:10.1093/ geront/gnp100

Caro, F., \& Morris, R. (2001). Maximizing the contributions of older people as volunteers. In S. Levkoff, Y. K. Chee, \& S. Noguchi (Eds.), Aging in good health (pp. 341-356). New York, NY: Springer Publishing Company.

Centers for Disease Control and Prevention. (2016). QuickStats: Percentage of adults with activity limitations, by age group and type of limitation - National Health Interview Survey, United States, 2014. Morbidity and Mortality Weekly Report, 65, 14. doi:10.15585/mmwr.mm6501a6 
Christensen, K., Doblhammer, G., Rau, R., \& Vaupel, J. (2009). Ageing populations: The challenges ahead. Lancet, 374, 1196-1208. doi:10.1016/S0140-6736(09)61460-4

Christensen, K., McGue, M., Petersen, I., Jeune, B., \& Vaupel, J. W. (2008, August 18). Exceptional longevity does not result in excessive levels of disability. Proceedings of the National Academy of Science, 105, 13274-13279. doi:10.1073/pnas.0804931105

Crimmins, E., \& Beltran-Sanchez, H. (2010). Mortality and morbidity trends: Is there compression of morbidity? Journal of Gerontology: Social Sciences, 66B, 75-86. doi:10.1093/geronb/ gbq088

Crimmins, E., Zhang, Y., \& Saito, Y. (2016). Trends over 4 decades in disability-free life expectancy in the United States. American Journal of Public Health, 106, 1287-1293. doi:10.2105/ AJPH.2016.303120

Federal Interagency Forum on Aging-Related Statistics. (2016). Older Americans 2016: Key indicators of well-being. Washington, DC: U.S. Government Publishing Office. Retrieved from https:/ / agingstats.gov/docs/LatestReport/Older-Americans-2016-Key-Indicators-of-WellBeing.pdf

Fitzgerald, F. (1994). The tyranny of health. New England Journal of Medicine, 331, 196-198. doi:10.1056/NEJM199407213310312

Friedan, B. (1993). The fountain of age. New York, NY: Simon \& Schuster.

Haber, D. (2005). Cultural diversity among older adults: Address health education. Educational Gerontology, 31, 683-697. doi:10.1080/03601270500217704

Hall, M. J., \& Owings, M. F. (2002). 2000 National hospital discharge survey. Advance data from vital and health statistics (No. 329). Hyattsville, MD: National Center for Health Statistics.

Hazzard, W. (2005). The conflict between biogerontology and antiaging medicine. Journal of the American Geriatrics Society, 53, 1434-1435. doi:10.1111/j.1532-5415.2005.53414.x

Hooyman, N., \& Kiyak, H. (2011). Social gerontology (9th ed.). Boston, MA: Allyn \& Bacon.

Jacob, J. (2002, March). Wellness programs help companies save on health costs. American Medical News, 32-33.

Jacob, M., Yee, L., Diehr, P., Arnold, A. M., Thielke, S. M., Cheeves, P. H., . . Newman, A. B. (2016). Can a healthy lifestyle compress the disabled period in older adults? Journal of the American Geriatrics Society, 64, 1952-1961. doi:10.1111/jgs.14314

Jonas, S. (2000). Talking about health and wellness with patients: Integrating health promotion and disease prevention into your practice. New York, NY: Springer Publishing Company.

Kamal, R., \& Cox, C. (2018, December 10). How has United States spending on healthcare changed over time? Retrieved from https:/ / www.healthsystemtracker.org/ chart-collection/u-s-spending-healthcare-changed-time

Kantor, E., Rehm, C., Haas, S., Chan, A., \& Giovannuci, E. (2015). Trends in prescription drug use among adults in the United States from 1999-2012. Journal of the American Medical Association, 314, 1818-1831. doi:10.1001/jama.2015.13766

Katz, J., \& Sanger-Katz, M. (2018). "The numbers are so staggering." Overdose deaths set a record. The New York Times, A11. Retrieved from https:/ / www.nytimes.com/interactive/2018/11/29/ upshot/fentanyl-drug-overdose-deaths.html

Landrum, M. B., Meara, E. R., Chandra, A., Guadagnoli, E., \& Keating, N. L. (2008). Is spending more always wasteful? The appropriateness of care and outcomes among colorectal cancer patients. Health Affairs, 27, 159-168. doi:10.1377/hlthaff.27.1.159

Lehman, B., Chapman, G., Franssen, F., Kog, G., \& Ruizer. R. (2016). Change the default to promote influenza vaccinations among health care workers. Vaccine, 34, 1389-1392.

Liu, H., Bravata, D. M., Olkin, I., Nayak, S., Roberts, B., Garber, A. M., \& Hoffman, A. R. (2007). Systematic review: The safety and efficacy of growth hormone in the healthy elderly. Annals of Internal Medicine, 146, 104-115. doi:10.7326/0003-4819-146-2-200701160-00005

McGinnis, J. M., Williams-Russo, P., \& Knickman, J. R. (2002). The case for more active policy attention to health promotion. Health Affairs, 21, 78-93. doi:10.1377/hlthaff.21.2.78

Monaghan, E. (2006, April 24). United States fares poorly in international patient survey. American Medical News, 5, 7. Retrieved from https:/ /amednews.com/article/20060424/ government/304249985/6

Munnell, A., \& Wu, A. (2012, October). Are aging baby boomers squeezing young workers out of jobs? (Research paper). Chestnut Hill, MA: Center for Retirement Research at Boston College. 
National Center for Health Statistics. (2016). Healthy People 2020: Midcourse review (pp. 31-7-31-8). Washington, DC: U.S. Department of Health and Human Services. Retrieved from https:/ / www.cdc.gov/nchs/data/hpdata2020/HP2020MCR-C31-OA.pdf

National Center for Health Statistics. (2017). Health, United States, 2016: With chartbook on longterm trends in health. Hyattsville, MD: Author.

National Council on Aging. (2002). American perceptions of aging in the 21st century. Washington, DC: Author. Document distributed by the National Council on Aging (www.ncoa.org)

Palmore, E. (2000). Ageism in gerontological language. Gerontologist, 40, 645. doi:10.1093/ geront/40.6.645

Pederson, K., Andersen, J., \& Soundergaard, J. (2012). General practice and primary health care in Denmark. Journal of American Board of Family Practice, 25, S34-S38. doi:10.3122/ jabfm.2012.02.110216

Pruchno, R. (2012). Not your mother's old age: Baby boomers at age 65. Gerontologist, 52, 149-152. doi:10.1093/geront/gns038

Qato, D. M., Alexander, G. C., Conti, R. M., Johnson, M., Schumm, P., \& Lindau, S. T. (2008). Use of prescription and over-the-counter medications and dietary supplements among older adults in the United States. Journal of the American Medical Association, 300, 2867-2878. doi:10.1001/jama.2008.892

Reeves, M., \& Rafferty, A. (2005). Healthy lifestyle characteristics among adults in the United States, 2000. Archives of Internal Medicine, 165, 854-857. doi:10.1001/archinte.165.8.854

Schoen, C., Osborn, R., How, S. K., Doty, M. M., \& Peugh, J. (2009, November 13). In chronic conditions: Experiences of patients with complex health care needs, in eight countries, 2008. Health Affairs, 28, w1-16. doi:10.1377/hlthaff.28.1.w1 (e-publication)

Tang, V., Zhav, S., Boscardin, J., Sudore, R., Covinsky, K., Walter, L. C., . . Finlayson, E. (2018). Functional status and survival rate after breast cancer surgery in nursing home residents. JAMA Surgery, 153(12), 1090-1096. doi:10.1001/jamasurg.2018.2736

Trafford, A. (2000, July 3). What will people do with the extra decade? Houston Chronicle, p. 3C.

U.S. Census Bureau. (2015). American Community Survey: Older Americans with a disability. Washington, DC: U.S. Department of Commerce.

U.S. Census Bureau. (2016). Current Population Survey: Annual social and economic supplement. Washington, DC: U.S. Department of Commerce.

U.S. Census Bureau. (2018, April). Current Population Survey: Annual social and economic supplement. Retrieved from https://www.acl.gov/sites/default/files/Aging\%20and\%20Disability\%20 in\%20America/2017OlderAmericansProfile.pdf

U.S. Department of Health and Human Services. (1979). Healthy people: The surgeon general's report on health promotion and disease prevention. Washington, DC: U.S. Government Publishing Office.

U.S. Public Health Service. (1980). Promoting health/preventing disease: Objective for the nation. Washington, DC: Author.

Varghese, R., \& Norman, P. (2004). Carotid endarterectomy in octogenarians. New Zealand Journal of Surgery, 74, 215-217. doi:10.1111/j.1445-2197.2004.02949.x

von Faber, M., Bootsma-van der Wiel, A., van Exel, E., Gussekloo, J., Lagaay, A. M., van Dongen, E., . . Westendorp, R. G. (2001). Successful aging in the oldest old: Who can be characterized as aged? Archives of Internal Medicine, 161, 2694-2700. doi:10.1001/archinte.161.22.2694

Wilson, D. (2007, April 15). Aging: Disease or business opportunity? The New York Times, pp. B1, B7. Retrieved from https://www.nytimes.com/2007/04/15/business/yourmoney/15aging .html 